\title{
Glass Formation, Phase Equilibria, and Thermodynamic Assessment of the Al-Ce-Co System Assisted by First-Principles Energy Calculations
}

\author{
MICHAEL C. GAO, NECIP ÜNLÜ, MAREK MIHALKOVIC, MICHAEL WIDOM, and \\ G.J. SHIFLET
}

This study investigates glass formation, phase equilibria, and thermodynamic descriptions of the Al-rich Al-Ce-Co ternary system using a novel approach that combines critical experiments, CALPHAD modeling, and first-principles (FP) calculations. The glass formation range (GFR) and a partial $500{ }^{\circ} \mathrm{C}$ isotherm are determined using a range of experimental techniques including melt spinning, transmission electron microscopy (TEM), electron probe microanalysis (EPMA), X-ray diffraction, and differential thermal analysis (DTA). Three stable ternary phases are confirmed, namely, $\mathrm{Al}_{8} \mathrm{CeCo}_{2}, \mathrm{Al}_{4} \mathrm{CeCo}$, and $\mathrm{AlCeCo}$, while a metastable phase, $\mathrm{Al}_{5} \mathrm{CeCo}_{2}$, was discovered. The equilibrium and metastable phases identified by the present and earlier reported experiments, together with many hypothetical ternary compounds, are further studied by FP calculations. Based on new experimental data and FP calculations, the thermodynamics of the Al-rich Al-Co-Ce system is optimized using the CALPHAD method. Application to glass formation is discussed in light of present studies.

DOI: $10.1007 / \mathrm{s} 11661-007-9259-6$

(C) The Minerals, Metals \& Materials Society and ASM International 2007

\section{INTRODUCTION}

BECAUSE of their promising applications where materials with high specific strength (ratio of fracture strength over density) are desirable, efforts to synthesize bulk Al-rich amorphous alloys have been made for more than a decade. Flexible (the word "flexible" is used because the as-spun amorphous ribbon did not break after a bending test of 180 deg at room temperature) Alrich Al-TM-RE $(\mathrm{TM}=$ transition metals, and $\mathrm{RE}=$ rare earth elements) glass-forming systems were discovered at the University of Virginia ${ }^{[1]}$ and elsewhere ${ }^{[2]}$ independently in 1988. Mechanisms for metallic glass formation and prediction of new glass compositions are ongoing areas of intensive research. Empirical rules based upon common features of experimentally identified glass forming systems suggest selecting elements with significant size differences and negative heats of mixing among the major constituents. ${ }^{[3]}$ The discovery of a large body of bulk metallic glasses (BMG) has recently made quantitative analysis of the atomic size distribution in the BMG systems possible. This led to the concept of efficient packing proposed in References 4

MICHAEL C. GAO, Research Associate, formerly with the Department of Materials Science and Engineering, University of Virginia, Charlottesville, VA 22904, is Senior Research Associate, Department of Materials Science and Engineering, Carnegie Mellon University, Pittsburgh, PA 15213. NECIP ÜNLÜ, Research Associate, and G.J. SHIFLET, Professor, are with the Department of Materials Science and Engineering, University of Virginia. Contact e-mail: gjs@virginia.edu MAREK MIHALKOVIC, Visiting Scientist, and MICHAEL WIDOM, Professor, are with the Department of Physics, Carnegie Mellon University, Pittsburgh, PA 15213.

Manuscript submitted March 18, 2007.

Article published online August 29, 2007. and 5. Both the empirical rules and the efficient packing concept help to find favorable combinations of constituent elements. However, what really matters is the critical cooling rate ${ }^{[6,7]}$ that is required to suppress crystallization of each equilibrium and metastable crystalline phase during solidification. The critical cooling rate is commonly and properly used to gage the glass forming ability of a particular alloy. It is often found that only a critical cooling rate of less than $\sim 10^{\circ} \mathrm{C} / \mathrm{s}$ can lead to formation of BMG.

To quantify the critical cooling rate for each glass forming system, a thermodynamic description is required for at least the equilibrium phases pertaining to metallic glass formation, and a quantitative understanding of atomic diffusion mechanisms is also necessary. ${ }^{[8,9]}$ Although the heat capacity for an amorphous solid can be measured with experiments, ${ }^{[10]}$ metallic glasses often readily crystallize with increasing temperature, and care must be taken to examine whether the sample remains fully amorphous during heat capacity measurement. On the other hand, the thermodynamic descriptions for the equilibrium phases for the system can be obtained by the CALPHAD (calculations of phase diagrams) method, once sufficient data on the phase diagram and thermochemistry are available.

Further, despite their high fracture strength, metallic glasses are rarely used as structural materials due to their shearing instability leading to shear bands resulting in catastrophic failure. Therefore, metallic glasses are often devitrified through controlled thermal annealing ${ }^{[11-13]}$ to obtain a crystalline-amorphous composite aimed at improving the fracture toughness. The art of the heat treatment is again closely related to the thermodynamics of the system in the amorphous and equilibrium states. With this in mind, the phase 
equilibria and the underlying thermodynamics of the Alrich $\mathrm{Al}-\mathrm{Fe}-\mathrm{Gd}^{[14]}$ system were studied by the current authors using a combined approach of critical experiments and the CALPHAD method. Because there is very limited information on the phase diagrams or the thermochemistry for the Al-TM-RE systems, an experimental phase equilibria study must be performed prior to the CALPHAD modeling.

In parallel to the Al-TM-RE ternary phase diagram study, the Al-RE binaries were also reinvestigated, because most were reported in the 1960s and 1970s and some remain incomplete or unknown. ${ }^{[15,16]}$ In the previous report on the Al-Ce system studied by Gao et al., ${ }^{[17]}$ it was shown that the $\beta \mathrm{Al}_{11} \mathrm{Ce}_{3} \cdot \mathrm{tI} 10$ compound ${ }^{[15,16]}$ should be treated as $\mathrm{Al}_{4}$ Ce.tI10 based on differential scanning calorimetry (DSC) measurements. (Structures are labeled using the notation \{Chemistry\}.\{Pearson Symbol\}, where the chemistry is the chemical formula of the phase of interest.) The differential thermal analysis (DTA) measurements and annealing/quenching tests ${ }^{[17]}$ also suggested a new $\mathrm{AlCe}_{2} . \mathrm{OP} 12$ phase, but only stable at high temperatures. Further, all the experimental observations and claims made in Reference 17 were supported from FP calculations employing electronic density functional theory. ${ }^{[18]}$ Based on critical experiments and FP calculations, both the Al-Ce and the Al-Nd binary systems were reoptimized and accurate and self-consistent sets of thermodynamic data were achieved. ${ }^{[17]}$ This unique approach combining critical experiments, ab-initio calculations, and CALPHAD modeling provides an effective and accurate way to determine phase diagrams and their corresponding quantitative thermodynamic descriptions. In this report, the same strategy was taken to investigate the Al-rich corner of the Al-Ce-Co ternary system.

\section{EXPERIMENTAL PROCEDURES}

One hundred and thirty four alloys, many of which are used to identify the glass formation range (GFR), as marked in Figure 1, were synthesized through arc melting pieces of $\mathrm{Al}$ (99.999 pct purity), Co (99.9995 pct), and $\mathrm{Ce}$ (99.9 pct) on a water-cooled copper hearth using a tungsten electrode in a partial argon atmosphere. Individual ingots were melted 5 to 6 times in total; each time the ingot was flipped over prior to melting to improve homogeneity. The weight loss after melting was found to be less than $1.0 \mathrm{wt}$ pct. All melting and casting of the alloys in a single-wheel melt spinner were done in a $\mathrm{He}$ atmosphere to prevent oxidization and improve heat conduction. The wheel was operated at a constant circumferential speed of $48 \mathrm{~m} / \mathrm{s}$. Following melt spinning, several experimental techniques including DSC, X-ray diffraction, and transmission electron microscopy (TEM) were used to check whether the as-spun ribbon was amorphous, partial amorphous, or crystalline. This resulted in the GFR, as shown in Figure 1, where earlier reported results ${ }^{[2,19]}$ have also been included.

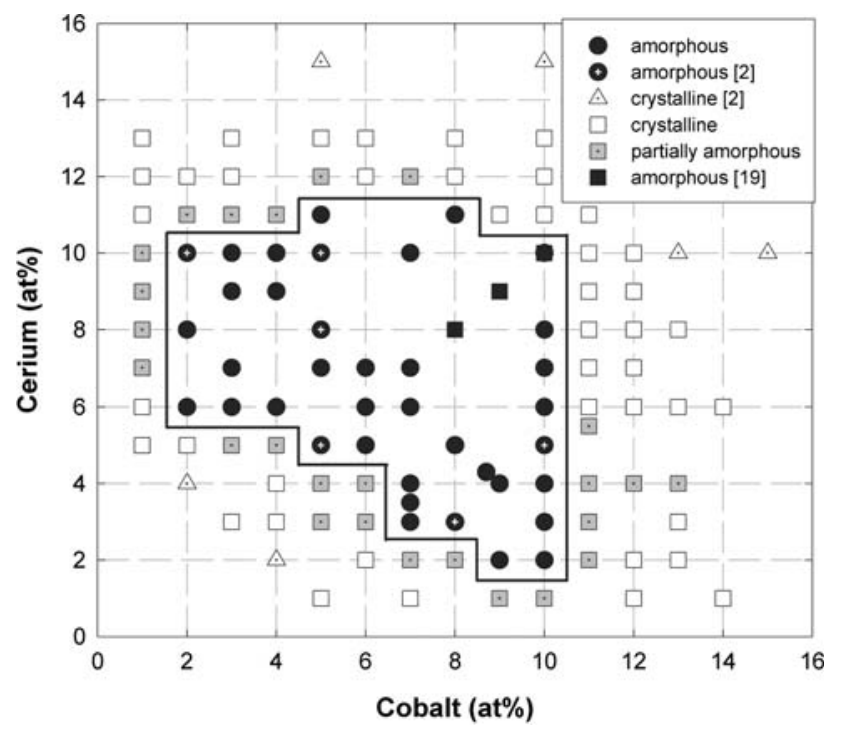

Fig. 1-GFR determined in the Al-rich Al-Ce-Co system, whose border is marked by the solid lines. The early reported work from Refs. 2 and 19 is also shown. The as-quenched alloys were synthesized with a constant circumferential speed of $48 \mathrm{~m} / \mathrm{s}$ using a single-wheel melt spinning technique.

Thirty-three alloys were selected for the partial $500{ }^{\circ} \mathrm{C}$ isotherm study. All the alloys were annealed at $500^{\circ} \mathrm{C}$ for 3 weeks under a partial pressure of argon. The annealed samples were quenched into cold water, ground and polished, and finally examined in a $\mathrm{LaB}_{6}$ and an FEG-scanning electron microscope (SEM) for microstructure analysis. Electron probe microanalysis (EPMA), using pure element samples as external standards, was employed to perform all chemical analysis. The accuracy of the EPMA measurement in this study is about 1 at. pct. The TEM sample preparation was published elsewhere. ${ }^{[13,14]}$

The DTA measurements were performed on all the 134 arc-melted samples in a Perkin-Elmer (Massachusetts, USA) DTA7 at a heating/cooling rate of $10 \mathrm{~K} / \mathrm{min}$ up to $1400{ }^{\circ} \mathrm{C}$ in a dynamic argon environment. For each sample, the heating/cooling cycle was repeated at least twice to ensure the reproducibility of all the thermal events. The DTA was calibrated with highpurity aluminum and gold with an uncertainty of $\pm 1{ }^{\circ} \mathrm{C}$ on the measured melting points after calibration. All the thermal events during the heating cycles are characterized by the heating onset temperature. The onset is defined by finding the intersection of the baseline and the extrapolated tangent at the inflection point of the leading edge of the peak. However, in certain cases, some thermal events were too weak to give a well-defined onset on heating, but still did show a well-defined cooling onset. In such cases, the peak temperature observed on heating is used.

\section{EXPERIMENTAL RESULTS}

The GFR determined in this study is shown in Figure 1, together with some earlier reported data. 
Alloys with compositions of $\mathrm{Al}_{99-y} \mathrm{Ce}_{y} \mathrm{Co}_{1}(y=8$ to 10 , all the composition are in atomic percent unless otherwise specified) were found to be partially amorphous in this study, as opposed to what was reported by Inoue et $a l .^{[2]}$ The discrepancy may be due to the difference in the cooling rate employed, e.g., the wheel speed and inert gas used in the chamber. The rationale is that these compositions can be melt spun into amorphous ribbons if a higher cooling rate (i.e., the higher wheel speed) is used. Therefore, the GFR determined in this study is referred to the specific wheel speed of $48 \mathrm{~m} / \mathrm{s}$ used. Figure 2(a) shows that as-spun $\mathrm{Al}_{90} \mathrm{Ce}_{3} \mathrm{Co}_{7}$ is truly amorphous, because no crystalline phase(s) was detected in the dark-field image and the selected area electron diffraction pattern. Figure 2(b) shows that the amorphous alloy completely decomposes into equilibrium phases of fcc-Al, $\mathrm{Al}_{11} \mathrm{Ce}_{3} \cdot \mathrm{oI} 28$, and $\mathrm{Al}_{9} \mathrm{Co}_{2} \cdot \mathrm{mP} 22$ after annealing at $500{ }^{\circ} \mathrm{C}$ for 24 hours.

The experimentally constructed Al-Ce-Co equilibrium $500{ }^{\circ} \mathrm{C}$ isotherm is shown in Figure 3 (the $600{ }^{\circ} \mathrm{C}$ isotherm assessed by Villars et al. can be found in Reference 20). There are three stoichiometric compounds confirmed, namely, $\mathrm{Al}_{8} \mathrm{CeCo}_{2} . \mathrm{oP} 44\left(\tau_{1}\right), \mathrm{Al}_{4} \mathrm{Ce}-$ Co.oP12 $\left(\tau_{2}\right)$, and AlCeCo.mC12 $\left(\tau_{3}\right)$. A metastable stoichiometric compound $\mathrm{Al}_{5} \mathrm{CeCO}_{2}$ (it is proposed to be isostructural with $\mathrm{Al}_{5} \mathrm{CeNi}_{2}$.oI16, based on current FP calculations) was also discovered in the present study (it is not shown in the equilibrium isotherm to avoid confusion). It was found that the Co solubility in the $\mathrm{Al}_{11} \mathrm{Ce}_{3} . \mathrm{oI} 28$ and $\alpha \mathrm{Al}_{3} \mathrm{Ce} . \mathrm{hP} 8$ binary compounds is negligible in agreement with the observation made by Zarechnyul et al. ${ }^{[21]}$ The same is true for Ce solubility in Al-Co binary compounds (not shown). However, the Co solubility in the $\mathrm{Al}_{2} \mathrm{Ce} . \mathrm{cF} 24$ was found to be $\sim 2.5$ at. pet $\mathrm{Co}$ at $500{ }^{\circ} \mathrm{C}$, while the previously reported Co solubility is $\sim 10$ at. pet Co. ${ }^{[21]}$ The solubility limit of $\mathrm{Co}$ in $\mathrm{Al}_{2} \mathrm{Ce}$ has significant influence on the phase relations and phase tie triangles in its vicinity. Details of the experimental results are presented subsequently.

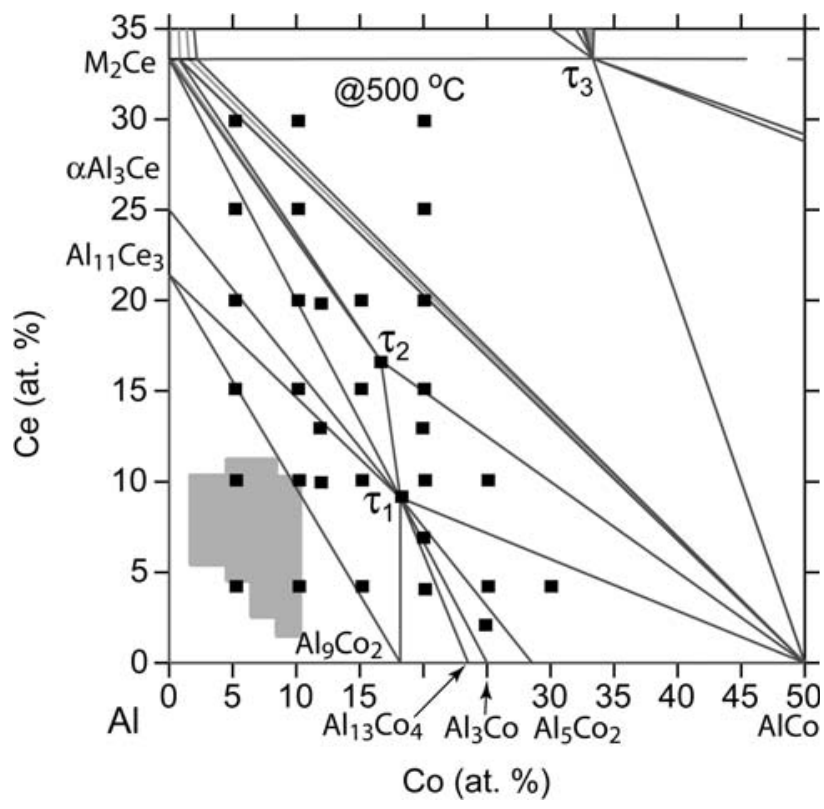

Fig. 3-Al-rich Al-Ce-Co $500{ }^{\circ} \mathrm{C}$ isotherm determined in this study. Samples chosen for equilibrium study are marked as filled squares. The shaded area highlights the observed GFR.

The EDX analysis on alloy $\mathrm{Al}_{65} \mathrm{Ce}_{25} \mathrm{Co}_{10}$ (not shown) demonstrates that the Co solubility in $\mathrm{M}_{2} \mathrm{Ce} . \mathrm{cF} 24$ is essentially zero, contradicting Zarechnyul's report of $\sim 5$ at. pet. ${ }^{[21]}$ It is concluded that Zarechnyul et al. ${ }^{[21]}$ overestimated the Co solubility in $\mathrm{M}_{2} \mathrm{Ce} . \mathrm{cF} 24$. The EPMA analysis on alloy $\mathrm{Al}_{60} \mathrm{Ce}_{30} \mathrm{Co}_{10}$ showed a $\mathrm{Co}$ solubility of $\sim 2.5$ at. pet at $500{ }^{\circ} \mathrm{C}$. Therefore, the Co solubility data obtained in the present report is selfconsistent and invalidates Zarechnyul's report. ${ }^{[21]}$ Direct evidence on the existence of metastable $\mathrm{Al}_{5} \mathrm{CeCO}_{2}$ is shown in Figure 4(a). There are four phases present in the microstructure, and all are visible because of the different contrast for each of them and confirmed
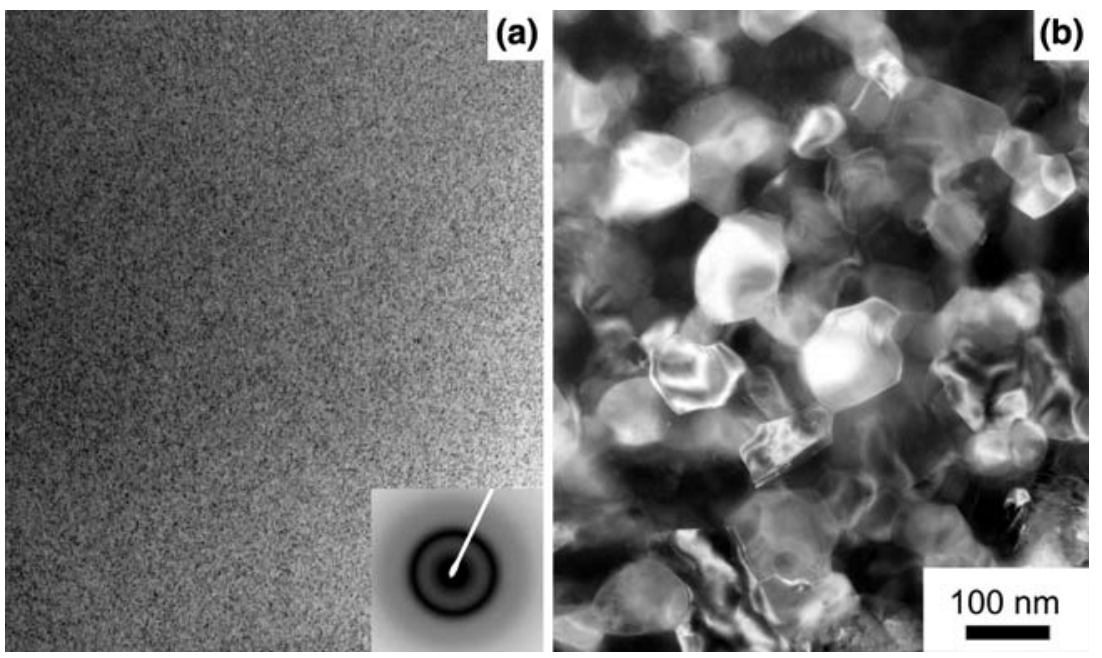

Fig. 2-(a) Dark-field TEM image of the as-spun amorphous alloy $\mathrm{Al}_{90} \mathrm{Ce}_{3} \mathrm{Co}_{7}$. The inset is the selected area electron diffraction pattern. (b) Bright-field TEM image of alloy $\mathrm{Al}_{90} \mathrm{Ce}_{3} \mathrm{Co}_{7}$ after annealing at $500{ }^{\circ} \mathrm{C}$ for 24 hours. The originally amorphous sample was fully crystallized into fcc- $\mathrm{Al}, \mathrm{Al}_{11} \mathrm{Ce}_{3}$, and $\mathrm{Al}_{9} \mathrm{Co}_{2}$ phases. 

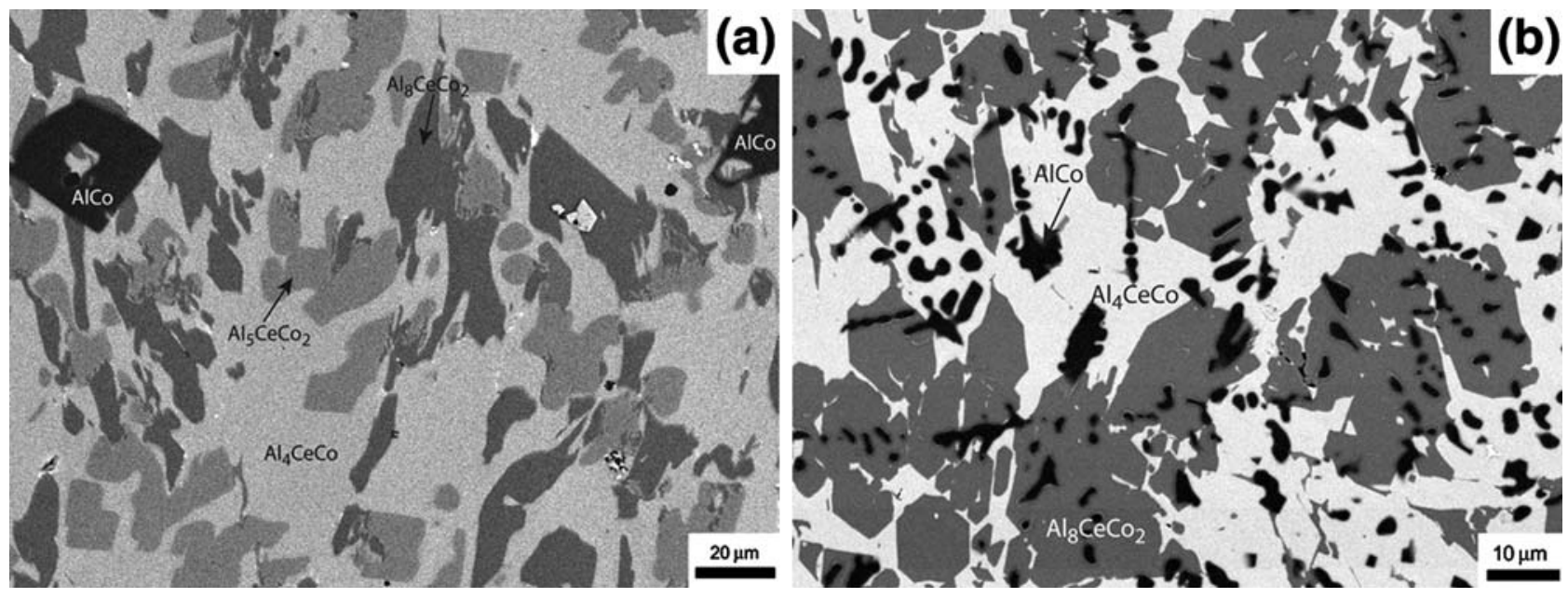

Fig. 4-BSE image of (a) alloy $\mathrm{Al}_{67} \mathrm{Ce}_{13} \mathrm{Co}_{20}$ and $(b) \mathrm{Al}_{65} \mathrm{Ce}_{10} \mathrm{Co}_{25}$ after annealing at $500{ }^{\circ} \mathrm{C}$ for 3 weeks. Note that $\mathrm{Al}_{5} \mathrm{CeCo}$. $\mathrm{OI} 16$ was not observed in (b), proving that $\mathrm{Al}_{5} \mathrm{CeCo}_{2} . \mathrm{OI} 16$ observed in (a) is metastable at $500{ }^{\circ} \mathrm{C}$.

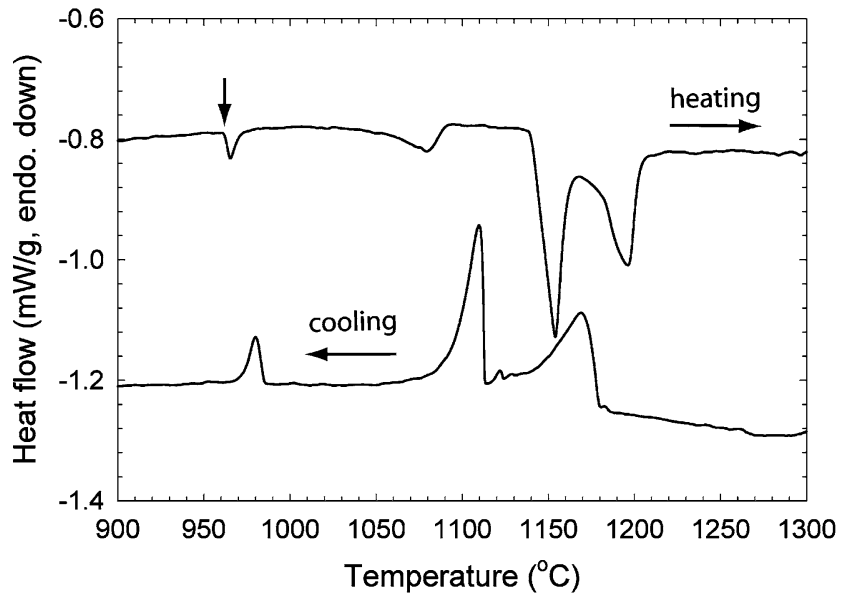

(a)

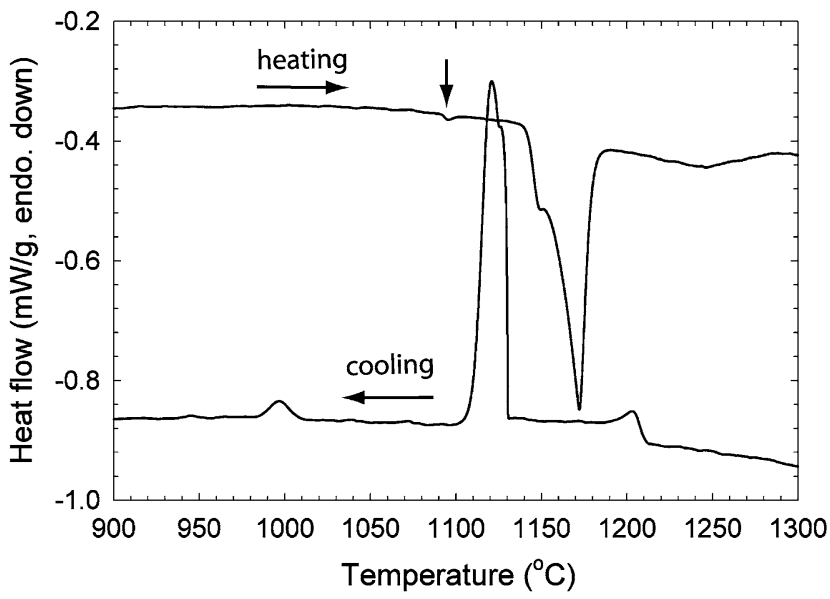

(b)

Fig. 5-DTA plots for $(a) \mathrm{Al}_{75} \mathrm{Ce}_{20} \mathrm{Co}_{5}$ and (b) $\mathrm{Al}_{70} \mathrm{Ce}_{20} \mathrm{Co}_{10}$. The arrow in (a) marks the onset temperature of the $\alpha / \beta \mathrm{Al}_{3} \mathrm{Ce}$ allotropic transition at $961{ }^{\circ} \mathrm{C}$. The arrow in (b) marks the onset temperature of reaction U6: $\beta \mathrm{Al}_{3} \mathrm{Ce}+\tau_{2} \leftrightarrow \mathrm{M}_{2} \mathrm{Ce}+\tau_{1}$ that occurs at $1089{ }^{\circ} \mathrm{C}$.

by their respective compositional EDX spectra. Because this phase was not observed in another alloy $\mathrm{Al}_{65} \mathrm{Ce}_{10} \mathrm{Co}_{25}$ (Figure 4(b)) nor in alloy $\mathrm{Al}_{65} \mathrm{Ce}_{25} \mathrm{Co}_{10}$ (not shown), it was concluded that $\mathrm{Al}_{5} \mathrm{CeCo}_{2}$ must be a metastable phase, at least at $500{ }^{\circ} \mathrm{C}$ and lower temperatures. A longer annealing at $500^{\circ} \mathrm{C}$ or at higher temperatures would be helpful to gain further experimental evidence on its metastability. However, it was not observed in Zarechnyul's $600{ }^{\circ} \mathrm{C}$ isotherm experiments. ${ }^{[21]}$

The overall DTA plots for most of the alloys are complex, which often consist of several thermal events, for example, in alloys $\mathrm{Al}_{75} \mathrm{Ce}_{20} \mathrm{Co}_{5}$ (Figure 5(a)) and $\mathrm{Al}_{70} \mathrm{Ce}_{20} \mathrm{Co}_{10}$ (Figure 5(b)). It is not immediately possible to identify which phases are involved in each thermal event if only the DTA plot is available. However, this can be done fairly easily once the thermodynamic descriptions for the system are determined (e.g., Figures 7 and 8). Based on the thermody- namic database developed in this study, the first thermal event with an onset temperature of $\sim 961{ }^{\circ} \mathrm{C}$ observed in $\mathrm{Al}_{75} \mathrm{Ce}_{20} \mathrm{Co}_{5}$ during the heating segment (Figure 5(a)) is concluded to reflect the allotropic transformation of $\alpha / \beta \mathrm{Al}_{3} \mathrm{Ce}$, which was recently identified by Gao et al. ${ }^{[17]}$ in their Al-Ce binary phase diagram study. This phase transition is also observed in alloy $\mathrm{Al}_{75} \mathrm{Ce}_{15} \mathrm{Co}_{10}$ whose first thermal event has a peak temperature of $970{ }^{\circ} \mathrm{C}$, further confirming the existence of allotropes of $\alpha / \beta \mathrm{Al}_{3} \mathrm{Ce}^{[17]}$ The first heating peak in alloy $\mathrm{Al}_{70} \mathrm{Ce}_{20} \mathrm{Co}_{10}$ occurs at $1089{ }^{\circ} \mathrm{C}$ (Figure 5(b)), and this event is also observed in several other alloys whose compositions lie within the tie triangles of $\alpha \mathrm{Al}_{3} \mathrm{Ce}-\tau_{1}-\mathrm{M}_{2} \mathrm{Ce}$ and $\alpha \mathrm{Al}_{3} \mathrm{Ce}-\tau_{1}-\mathrm{Al}_{11} \mathrm{Ce}_{3}$. Thus, it is concluded that this event must belong to an invariant reaction, and the current thermodynamic calculations actually predict that it results from the phase relation change, namely, $\beta \mathrm{Al}_{3} \mathrm{Ce}+\tau_{2} \leftrightarrow \mathrm{M}_{2} \mathrm{Ce}+$ $\tau_{1}\left(\mathrm{U}_{6}\right.$ in Table IV). 


\section{FIRST-PRINCIPLES ENERGY CALCULATION}

The Al-Ce-Co ternary system and its constituent binary systems are further analyzed using first-principles (FP) calculations that employ the plane-wave code VASP ${ }^{[22,23]}$ which solves for the electronic band structure using electronic density functional theory and PAW potentials. $^{[2]}$ Two choices are available for the $\mathrm{Ce}$ potential, a "standard" version in which the entire set of $f$-levels is treated within the valence band and a trivalent version (named "Ce_3") in which some $f$-electrons are kept frozen in the core. Because the trivalent Ce_3 potential incorrectly predicts a positive enthalpy of formation $\left(\Delta H_{f}=+5.7 \mathrm{~kJ} / \mathrm{mol}\right)^{[25]}$ for the stable $\mathrm{C} 15-\mathrm{CeCo}_{2} \cdot \mathrm{cF} 24$ compound, the standard Ce potential was used throughout the Al-Ce-Co system. The exchange-correlation functional used is the PerdewBurke-Ernzerhof (PBE) gradient approximation. ${ }^{[26]}$ Reciprocal space ( $k$-point) meshes are increased and all structures are fully relaxed (both lattice parameters and atomic coordinates) until energies converge to a precision of $1 \mathrm{meV} /$ atom. The plane-wave energy cutoff was held constant at $300 \mathrm{eV}$, the default for the $\mathrm{Ce}$ potential. All calculations were performed using the "Accurate" setting, which avoids wrap-around errors. Spin polarization was considered in all calculations other than pure $\mathrm{Al}$.

To obtain $T=0 \mathrm{~K}$ enthalpy of formation values $\Delta H_{f}$, a composition-weighted average of the pure elemental cohesive energies is subtracted from the cohesive energy of a given compound. Stable structures are identified as the vertices of the convex hull of a scatter plot of $\Delta H_{f} v s$ composition. Points above the convex hull represent thermodynamically unstable structures, though they may be metastable or hightemperature stable in some cases. Details of the relaxed structures and their enthalpies can also be found on the worldwide web. ${ }^{[27]}$

Resulting enthalpies of formation are displayed in Figure 6 for Al-Ce-Co. The lattice stability of Al, Ce, and Co can be found in References 17 and 28. The enthalpy of formation for the Al-Ce binary system was reported in Reference 17. The FP calculations on the Al-Co system are reported in Reference 28. For each pure element, the present calculations correctly identify the low-temperature and known high-temperature phases. For each binary and the ternary, however, disagreements are found between the calculated phase diagrams and the experimentally established ones. Some of the disagreements probably reflect poor approximations made in the calculated cohesive energies, for example, the use of nonrelativistic quantum mechanics. Other, stronger disagreements require further study, both theoretical and experimental. The binary diagrams are fairly well reproduced, but the agreement in the case of $\mathrm{Al}-\mathrm{Ce}$ is less impressive than in other studies of non-RE-containing alloys. ${ }^{[2]}$ The binary Al-Ce phase diagram was already discussed in Reference 17.

Binary Al-Co exhibits several interesting structures in the Al-rich region. Experimental investigation of the phase diagram is ongoing, with the greatest uncertainty

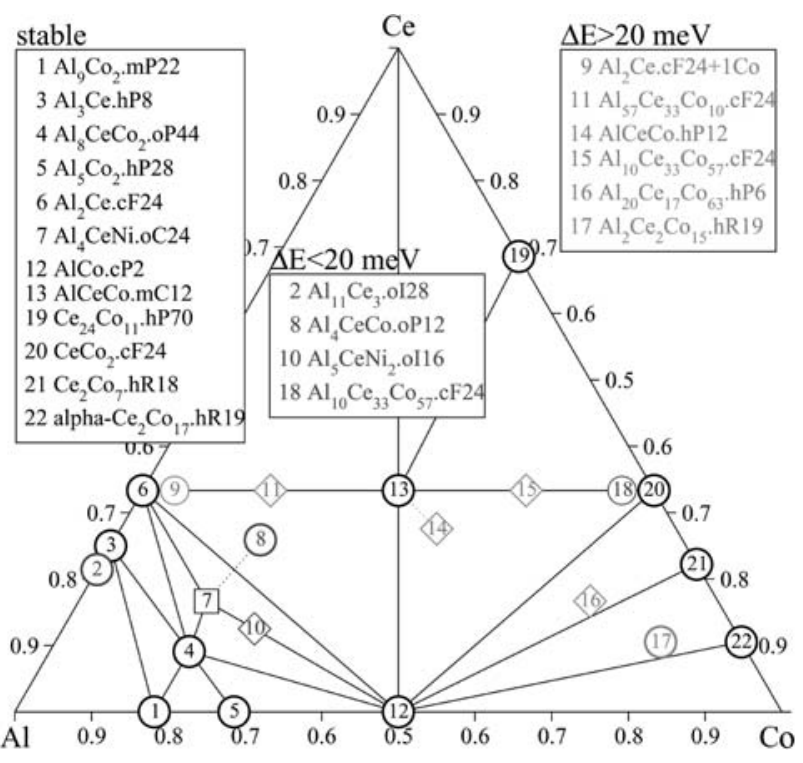

Fig. 6-Convex hull and metastable/unstable phases of the Al-Ce-Co system. The plotting symbol notation is as follows: heavy circles for known stable binary phases; light circles for known high-temperature phases; diamonds for known metastable phases; triangles for known high-pressure phases; and squares for imperfectly known, unknown, or hypothetical structures. Tie-lines run along convex hull edges, joining low enthalpy structures at the vertices of the convex hull.

in the composition range $\mathrm{Al}_{13} \mathrm{Co}_{4}-\mathrm{Al}_{3} \mathrm{Co}$, where a variety of "quasi-crystal approximant" structures are observed. ${ }^{[30-34]}$ The well-known stable phases $\mathrm{Al}_{9} \mathrm{Co}_{2} \cdot \mathrm{mP} 22$ and $\mathrm{Al}_{5} \mathrm{Co}_{2} \cdot \mathrm{hP} 28$ are found on either side of this problematic composition range. Further discussion of the composition range $\mathrm{Al}_{13} \mathrm{Co}_{4}-\mathrm{Al}_{3} \mathrm{Co}$ may be found in Reference 28.

The Ce-Co yields excellent agreement with the established phase diagram provided the standard Ce potential is used, as opposed to trivalent Ce_3 in which the $f$-level is kept frozen. The calculated enthalpy of formation and lattice parameters are listed in Table I, and the latter agree with experimentally determined values. The cluster of reported stable phases from $\mathrm{CeCo}_{3}$ to $\mathrm{Ce}_{5} \mathrm{Co}_{19}$ is thermodynamically implausible, and the present calculation is more consistent with a single low-temperature phase (possibly $\mathrm{Ce}_{2} \mathrm{Co}_{7}$ ) together with two high-temperature or metastable phases on either side of it. The hP6 structure of $\mathrm{CeCo}_{5}$ is properly identified as a hightemperature phase.

The ternary diagram is well reproduced. The enthalpies of formation data set for stable and hypothetical compounds are listed in Table II together with the calculated lattice parameters, which closely agree with the experimentally determined values. The known stable phases that are confirmed are as follows: $\mathrm{Al}_{8} \mathrm{Ce}-$ $\mathrm{Co}_{2}$.oP44, which is recognized as a decagonal quasicrystal approximant, ${ }^{[21,35]}$ and $\mathrm{AlCeCo.mC12}$. The alternate reported structure $\mathrm{AlCeCo.hP12}$ is high in energy by $144 \mathrm{meV} /$ atom and most likely is metastable. At the composition of $\mathrm{Al}_{4} \mathrm{CeCo.oP} 12$, a different structure was found, namely, $\mathrm{Al}_{4} \mathrm{CeNi}$.oC24 lower in energy by $5 \mathrm{meV} /$ atom. Because it was not possible to perfectly 
Table I. Enthalpies of Formation of Stable Compound Phases, $\Delta H_{f}$, at $T=0 \mathrm{~K}$ for the Ce-Co System Calculated by FP and a Comparison of Calculated Lattice Parameters with Experimental Data

\begin{tabular}{|c|c|c|c|c|c|c|}
\hline \multirow[b]{3}{*}{ Compound* } & \multirow[b]{3}{*}{ Pearson Symbol-Prototype } & \multirow[b]{3}{*}{$\Delta H_{f}(\mathrm{~kJ} / \mathrm{mol}$ of atoms $)$} & \multicolumn{4}{|c|}{ Lattice Parameters $(\AA)$} \\
\hline & & & \multicolumn{2}{|c|}{$\begin{array}{c}\text { Ab Initio } \\
\text { (This Work) }\end{array}$} & \multicolumn{2}{|c|}{ Experiment $^{[62]}$} \\
\hline & & & $a$ & $c$ & $a$ & $c$ \\
\hline${ }^{\mathrm{s}} \mathrm{Ce}_{24} \mathrm{Co}_{11}$ & $\mathrm{hP} 70-\mathrm{Ce}_{24} \mathrm{Co}_{11}$ & -13.46 & 9.351 & 20.814 & 9.587 & 21.825 \\
\hline${ }^{\mathrm{s}} \mathrm{CeCO}_{2}$ & $\mathrm{cF} 24-\mathrm{Cu}_{2} \mathrm{Mg}$ & -24.09 & 7.058 & - & 7.160 & - \\
\hline${ }^{1 \mathrm{t}} \alpha \mathrm{Ce}_{2} \mathrm{Co}_{17}$ & $\mathrm{hR} 19-\mathrm{Th}_{2} \mathrm{Zn}_{17}$ & -8.23 & 8.318 & 12.119 & 8.378 & 12.206 \\
\hline ht $\beta \mathrm{Ce}_{2} \mathrm{Co}_{17}$ & $\mathrm{hP} 38-\mathrm{Th}_{2} \mathrm{Ni}_{17}$ & -7.75 & 8.315 & 8.080 & 8.378 & 8.1317 \\
\hline${ }^{\mathrm{s}} \mathrm{Ce}_{5} \mathrm{Co}_{19}$ & $\mathrm{hR} 24-\mathrm{Ce}_{5} \mathrm{Co}_{19}$ & -15.2 & 4.872 & 49.148 & 4.948 & 48.7434 \\
\hline${ }^{\mathrm{s}} \mathrm{CeCO}_{3}$ & $\mathrm{hR} 12-\mathrm{Be}_{3} \mathrm{Nb}$ & -17.44 & 4.887 & 24.900 & 4.964 & 24.814 \\
\hline${ }^{\mathrm{ht}} \mathrm{CeCO}_{5}$ & hP6-CaCu 5 & -10.41 & 4.876 & 4.022 & 4.920 & 4.029 \\
\hline${ }^{\mathrm{s}} \mathrm{Ce}_{2} \mathrm{Co}_{7}$ & $\mathrm{hR} 18-\mathrm{Co}_{7} \mathrm{Er}_{2}$ & -16.67 & 4.882 & 37.103 & 4.940 & 36.52 \\
\hline
\end{tabular}

"s: stable, lt: low-temperature phase, and ht: high-temperature phase.

Table II. Enthalpies of Formation of Ternary Compound Phases, $\Delta H_{f}(\mathrm{~kJ} / \mathrm{mol}$ of Atoms), at $T=0 \mathrm{~K}$ for Al-Ce-Co System Calculated by FP; the Deviation from the Convex Hull $(\mathrm{kJ} / \mathrm{mol}$ of Atoms) is Marked as $\Delta E$; the Calculated Lattice Parameter is Also Shown in Comparison with the Available Experimental Data

\begin{tabular}{|c|c|c|c|c|c|c|c|c|c|}
\hline \multirow[b]{3}{*}{ Phase $^{*}$} & \multirow{3}{*}{$\begin{array}{c}\text { Pearson } \\
\text { Symbol-Prototype }\end{array}$} & \multirow[b]{3}{*}{$\Delta H_{f}$} & \multirow[b]{3}{*}{$\Delta E$} & \multicolumn{6}{|c|}{ Lattice Parameters $(\AA)$} \\
\hline & & & & \multicolumn{3}{|c|}{ Ab Initio (This Work) } & \multicolumn{3}{|c|}{ Experiment $^{[62]}$} \\
\hline & & & & $a$ & $b$ & $c$ & $a$ & $b$ & $c$ \\
\hline${ }^{\mathrm{s}} \mathrm{Al}_{8} \mathrm{CeCO}_{2}$ & $\mathrm{oP} 44-\mathrm{Al}_{8} \mathrm{CeCo}_{2}$ & -46.26 & 0.0 & 14.357 & 12.389 & 3.994 & 14.30 & 12.41 & 4.12 \\
\hline${ }^{\mathrm{s}} \mathrm{Al}_{4} \mathrm{CeCo}$ & $\mathrm{oP} 12-\mathrm{Al}_{4} \mathrm{CeCo}$ & -47.63 & 0.5 & 7.594 & 4.041 & 6.791 & 7.59 & 4.048 & 7.014 \\
\hline \multirow[t]{2}{*}{ s $\mathrm{AlCeCo}$} & $\mathrm{mC} 12-\mathrm{AlCeCo}$ & -50.51 & 0.0 & 11.066 & 4.429 & 4.726 & 11.098 & 4.410 & 4.807 \\
\hline & & & & $\alpha, \gamma=\varsigma$ & eg; $\beta=$ & $.44 \mathrm{deg}$ & $\alpha, \gamma=\varsigma$ & $\operatorname{leg} ; \beta=$ & $4.61 \mathrm{deg}$ \\
\hline${ }^{\mathrm{h}} \mathrm{Al}_{4} \mathrm{CeCo}$ & oC24-Al ${ }_{4} \mathrm{CeNi}$ & -48.12 & 0.0 & 4.094 & 15.506 & 6.648 & - & - & - \\
\hline${ }^{\mathrm{h}} \mathrm{AlCeCo}$ & hP9-AlNdNi & -46.34 & 4.2 & 6.824 & - & 4.011 & - & - & - \\
\hline${ }^{\mathrm{h}} \mathrm{AlCeCo}$ & hP12-AlCeCo & -36.61 & 13.9 & 5.461 & - & 8.300 & - & - & - \\
\hline${ }^{\mathrm{h}} \mathrm{Al}_{3} \mathrm{CeCo}$ & oP20-Al ${ }_{3} \mathrm{NiY}$ & -48.22 & 1.9 & 8.130 & 4.031 & 10.770 & - & - & - \\
\hline${ }^{\mathrm{h}} \mathrm{Al}_{8} \mathrm{CeCo}_{4}$ & $\mathrm{tI} 26-\mathrm{Al}_{8} \mathrm{CeFe}_{4}$ & -47.71 & 4.1 & 8.588 & - & 5.109 & - & - & - \\
\hline${ }^{\mathrm{m}} \mathrm{Al}_{5} \mathrm{CeCO}_{2}$ & oI16- $\mathrm{Al}_{5} \mathrm{CeNi}_{2}$ & -48.88 & 1.5 & 7.130 & 9.334 & 3.947 & - & - & - \\
\hline${ }^{\mathrm{h}} \mathrm{Al}_{7} \mathrm{Ce}_{6} \mathrm{Co}_{7}$ & $\mathrm{tP} 40-\mathrm{Al}_{7} \mathrm{Co}_{6} \mathrm{Pr}_{7}$ & -44.54 & 4.3 & 13.175 & - & 4.289 & - & - & - \\
\hline${ }^{\mathrm{u}} \mathrm{Al}_{2} \mathrm{Ce}_{2} \mathrm{Co}_{15}$ & $\mathrm{hR} 19-\mathrm{Al}_{2} \mathrm{Ce}_{2} \mathrm{Co}_{15}$ & -16.16 & 4.3 & 8.355 & - & 12.283 & 8.44 & - & 12.30 \\
\hline
\end{tabular}

reproduce the Al-Ce binary diagram, it is difficult to assert which structure is the true low energy state. Rather, further experimental and theoretical effort is required to resolve the matter. Finally, it was found that $\mathrm{Al}_{5} \mathrm{CeNi}_{2}$.oI16 has a low energy of only $15 \mathrm{meV} /$ atom, indicating a possible metastable or high-temperature phase. This is possibly the structure for a metastable phase obtained in the experimental portion of this work.

Further calculations were performed to examine the composition ranges of all $\mathrm{Al}-\mathrm{Ce}$ and $\mathrm{Ce}-\mathrm{Co}$ binary structures as they extend into the ternary through substitutions of $\mathrm{Al}$ and Co atoms. All substitutions were found to be highly unfavorable, with the highest concentration (i.e., lowest energy) found in the case of $\mathrm{CeCO}_{2}$. For this compound, the substitution energy is found to be $\Delta E=0.36 \mathrm{eV}$. At $T=500 \mathrm{~K}$, the thermal energy $\mathrm{k}_{\mathrm{B}} T=0.043 \mathrm{eV}$, so it is estimated that a fraction $\exp (-0.36 \mathrm{eV} / 0.043 \mathrm{eV})=0.002$ of the Al atoms will be substituted by Al atoms. This behavior differs markedly from an alloy such as $\mathrm{Al}-\mathrm{Ca}-\mathrm{Cu}$, where $\mathrm{Al}$ and $\mathrm{Cu}$ easily substitute for each other. ${ }^{[36]}$ Evidently, the filled $d$-level of the noble metal $\mathrm{Cu}$ lets it more easily substitute for Al than is the case for the transition metal Co, with its partially filled $d$-level. ${ }^{[37]}$

\section{THERMODYNAMIC MODELS}

The Gibbs free energy of individual phases is described by sublattice models ${ }^{[38]}$ and is defined relative to the standard element reference (SER), i.e., the enthalpies of the pure elements in their defined reference phase at $298.15 \mathrm{~K}$ and $1 \mathrm{~atm}$. All the disordered solutions including the liquid are modeled with a single sublattice, with the Gibbs energy expressed as for a ternary complete disordered solution (e.g., liquid) with components $\mathrm{Al}, \mathrm{Ce}$, and $\mathrm{Co}$ : 


$$
\begin{aligned}
G^{\phi}= & \sum_{\mathrm{i}=\mathrm{Al}, \mathrm{Ce}, \mathrm{Co}} x_{\mathrm{i}}^{o} G_{\mathrm{i}}^{\phi}+\mathrm{R} T \sum_{\mathrm{i}=\mathrm{Al}, \mathrm{Ce}, \mathrm{Co}} x_{\mathrm{i}} \ln x_{\mathrm{i}} \\
& +{ }^{e x} G_{\mathrm{Al}, \mathrm{Ce}, \mathrm{Co}}^{\phi}+{ }^{\operatorname{mag}} G_{\mathrm{Al}, \mathrm{Ce}, \mathrm{Co}}^{\phi}
\end{aligned}
$$

where ${ }^{o} G_{\mathrm{i}}^{\phi}$ is the molar Gibbs energy of the pure element $i$ in the structure of phase $\phi$ in the nonmagnetic state, taken from the values tabulated by Dinsdale, ${ }^{[39]}$ and $x_{\mathrm{i}}$ is the mole fraction of each component. (The colon in the subscript is used to separate different sublattices, while the comma indicates solid solution.) The excess Gibbs energy, ${ }^{e x} G_{\mathrm{Al}, \mathrm{Ce}, \mathrm{Co}}^{\phi}$, is expressed in Redlich-Kister-Muggianu polynomial form: ${ }^{[40,41]}$

$$
\begin{aligned}
{ }^{e x} G_{\mathrm{Al}, \mathrm{Ce}, \mathrm{Co}}^{\phi}= & x_{\mathrm{Al}} x_{\mathrm{Ce}} \sum_{k=0}^{k}{ }^{k} L_{\mathrm{Al}, \mathrm{Ce}}^{\phi}\left(x_{\mathrm{Al}}-x_{\mathrm{Ce}}\right)^{k} \\
& +x_{\mathrm{Ce}} x_{\mathrm{Co}} \sum_{k=0}^{k}{ }^{k} L_{\mathrm{Ce}, \mathrm{Co}}^{\phi}\left(x_{\mathrm{Ce}}-x_{\mathrm{Co}}\right)^{k} \\
& +x_{\mathrm{Al}} x_{\mathrm{Co}} \sum_{k=0}^{k}{ }^{k} L_{\mathrm{Al}, \mathrm{Co}}^{\phi}\left(x_{\mathrm{Al}}-x_{\mathrm{Co}}\right)^{k} \\
& +x_{\mathrm{Al}} x_{\mathrm{Ce}} x_{\mathrm{Co}}\left({ }^{0} L_{\mathrm{Al}, \mathrm{Ce}, \mathrm{Co}}^{\phi} x_{\mathrm{Al}}+{ }^{1} L_{\mathrm{Al}, \mathrm{Ce}, \mathrm{Co}} x_{\mathrm{Ce}}\right. \\
& \left.+{ }^{2} L_{\mathrm{Al}, \mathrm{Ce}, \mathrm{Co}}^{\phi} x_{\mathrm{Co}}\right)
\end{aligned}
$$

where ${ }^{k} L_{\mathrm{i}, \mathrm{j}}^{\phi}$ where ${ }^{k} L_{\mathrm{i}, \mathrm{j}}^{\phi}$ are the binary interaction parameters ( $k$ is an integer), which are taken directly from individually assessed edge binary databases; and ${ }^{k} L_{\mathrm{Al}, \mathrm{Ce}, \mathrm{Co}}^{\phi}$ are the ternary interaction parameters, which are to be optimized in this study. Both the binary and ternary interaction parameters have the following general form:

$$
{ }^{k} L^{\phi}={ }^{k} a+{ }^{k} b T+{ }^{k} c T \ln (T)+{ }^{k} d T^{2}+{ }^{k} e T^{-1}+{ }^{k} f T^{-3}
$$

The magnetic contribution to the Gibbs energy $\left({ }^{\operatorname{mag}} G^{\phi}\right)$ for all the ternary compound phases in the Alrich corner was set to zero, because they all order at very low temperatures less than $100 \mathrm{~K}$. It is only significant for the Ce-Co binary and Co-rich ternary alloys, neither of which are the focus of this study.

Stoichiometric compounds are modeled as if the enthalpy and entropy are constants and only one element occupies one sublattice. For example, the Gibbs free energy for a ternary stoichiometric compound $\mathrm{Al}_{x} \mathrm{Ce}_{y} \mathrm{Co}_{z}(x, y$, and $z$ denote the chemical formula) is modeled as ( $\mathrm{J} / \mathrm{mole}$ of total atoms)

$$
\begin{aligned}
G^{\mathrm{Al}_{x} \mathrm{Ce}_{y} \mathrm{Co}_{z}}= & \frac{x}{x+y+z}{ }^{o} G_{\mathrm{Al}}^{\mathrm{fcc}} \\
& +\frac{y}{x+y+z}{ }^{o} G_{\mathrm{Ce}}^{\mathrm{fcc}}+\frac{z}{x+y+z}{ }^{o} G_{\mathrm{Co}}^{\mathrm{hcp}}+a+b T
\end{aligned}
$$

where $a$ and $b$ are the parameters to be determined, namely, the enthalpies of formation and entropies of formation for the compound $G^{\mathrm{Al}_{x} \mathrm{Ce}_{y} \mathrm{Co}_{z}}$, respectively.
The terms ${ }^{o} G_{\mathrm{Al}}^{\mathrm{fcc}},{ }^{o} G_{\mathrm{Ce}}^{\mathrm{fcc}}$, and ${ }^{o} G_{\mathrm{Co}}^{\mathrm{hcp}}$ are the Gibbs energies of the pure components, $\mathrm{Al}, \mathrm{Ce}$, and $\mathrm{Co}$, with respect to its enthalpies in the SER state, respectively. Note that both $\mathrm{Ce}$ and $\mathrm{Co}$ have several allotropes in the solid state. At the SER state, both Al and Ce have a crystal structure of fcc, while Co has a crystal structure of hep.

The Gibbs energy of those binary $(\mathrm{Al}, \mathrm{Co})_{x} \mathrm{Ce}_{y}$ compound phases that have ternary solubility (i.e., Al and Co substitute for each other in ternary phase) is expressed as

$$
\begin{aligned}
G^{(\mathrm{Al}, \mathrm{Co})_{x} \mathrm{Ce}_{y}}= & \sum_{\mathrm{i}=\mathrm{Al}, \mathrm{Co}} y_{\mathrm{i}}^{o} G_{\mathrm{i}: \mathrm{Ce}}^{(\mathrm{Al}, \mathrm{Co})_{x} \mathrm{Ce}_{y}}+\frac{x}{x+y} \mathrm{R} T \sum_{\mathrm{i}=\mathrm{Al}, \mathrm{Co}} y_{\mathrm{i}} \ln y_{\mathrm{i}} \\
& +y_{\mathrm{Al}} y_{\mathrm{Co}} \sum_{k=0}^{k}{ }^{k} L_{\mathrm{Al}, \mathrm{Co}: \mathrm{Ce}}^{(\mathrm{Al}, \mathrm{Ce})_{x} \mathrm{Ce}_{y}}\left(y_{\mathrm{Al}}-y_{\mathrm{Co}}\right)^{k}
\end{aligned}
$$

where ${ }^{k} L_{\mathrm{Al}, \mathrm{Co}: \mathrm{Ce}}^{(\mathrm{Al}, \mathrm{Co})_{x} \mathrm{Ce}_{y}}$ are the interaction parameters and have a form in Eq. [3]. The ${ }^{o} G_{\mathrm{Al}: \mathrm{Ce}}^{(\mathrm{Al},)_{x} \mathrm{Ce}_{y}}$ and ${ }^{o} G_{\mathrm{Co}: \mathrm{Ce}}^{(\mathrm{Al})_{x} \mathrm{Ce}_{y}}$ represent the Gibbs energy of the compound $\mathrm{Al}_{x} \mathrm{Ce}_{y}$ and $\mathrm{Co}_{x} \mathrm{Ce}_{y}$, respectively. These two expressions were obtained from the binary assessments without change during optimization. Only the interac-

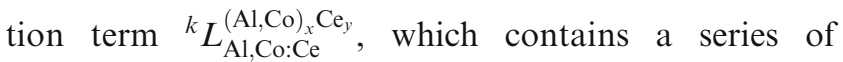
parameters $a, b, c \ldots$ (Eq. [3]), was optimized in this study to obtain best fitting between the calculated phase diagram and experimental data achieved in this study and those assessed in Reference 21. It was found in Reference 21 and the present study that in the Al-rich corner, only $\mathrm{Al}_{2} \mathrm{Ce} . \mathrm{cF} 24$ extends into ternary solubility, but $\mathrm{CeCo}_{2} . \mathrm{cF} 24$ also has significant ternary solubility. ${ }^{[21]}$ Therefore, both are treated as one ternary phase $\mathrm{M}_{2} \mathrm{Ce}(\mathrm{M}=\mathrm{Al}, \mathrm{Co})$ with a two-sublattice model of $(\mathrm{Al}, \mathrm{Co})_{2}(\mathrm{Ce})_{1}$. This choice makes physical sense, because (1) both $\mathrm{Al}_{2} \mathrm{Ce}$ and $\mathrm{CeCo}_{2}$ are $\mathrm{A}_{2} \mathrm{~B}$-type Laves phases (prototype $\mathrm{Cu}_{2} \mathrm{Mg}$, Pearson symbol cF24), and their lattices consist of only two crystallographic sites (A atoms occupy Wyckoff sites $16 \mathrm{~d}$ and B atoms occupy 8a); and (2) substitution between $\mathrm{Al}$ and $\mathrm{Co}$ in the $16 \mathrm{~d}$ site is energetically favored and is confirmed, while substitution between $\mathrm{Al} / \mathrm{Co}$ and $\mathrm{Ce}$ in the $8 \mathrm{a}$ site is not found in Reference 21 and this study.

The Al-Co system was thermodynamically optimized by Dupin and Ansara, ${ }^{[42]}$ and their thermodynamic descriptions were directly used without modification. The stable intermetallic compounds reported for the Al-Co binary system include $\mathrm{Al}_{9} \mathrm{Co}_{2} \cdot \mathrm{mP} 22, \mathrm{Al}_{13}$ $\mathrm{Co}_{4} \cdot \mathrm{mC} 32, \mathrm{Al}_{3} \mathrm{Co} . \mathrm{oP} 16, \mathrm{Al}_{5} \mathrm{Co}_{2} \cdot \mathrm{hP} 28$, and $\mathrm{AlCo} . \mathrm{PP} 2$.

The Ce-Co binary was thermodynamically assessed by $\mathrm{Su}$ et al., ${ }^{[43]}$ and two different approaches were offered in the assessment. The first one treated both $\mathrm{Ce}_{2} \mathrm{Co}_{17}$ and $\mathrm{CeCo}_{5}$ as stoichiometric compounds, and the $\mathrm{CeCo}_{5}$.hP6 transforms into $\mathrm{Ce}_{5} \mathrm{Co}_{19}$ and $\mathrm{Ce}_{2} \mathrm{Co}_{17}$ via eutectoid reaction. The other treatment treated $\mathrm{Ce}_{2} \mathrm{Co}_{17}$ and $\mathrm{CeCo}_{5}$ as a single phase with different compositions, and $\mathrm{CeCo}_{5} \cdot \mathrm{hP} 6$ transforms into $\mathrm{Ce}_{5} \mathrm{Co}_{19} \cdot \mathrm{hR} 24$ and $\mathrm{Ce}_{2} \mathrm{Co}_{17}$.hR19 via spinodal decomposition, as suggested in Reference 44. However, the second one remains controversial, as argued in Reference 45 . In the established $\mathrm{Ce}$-Co phase diagram, ${ }^{[15,16]}$ several compounds 
with close chemistry $\left(\mathrm{CeCo}_{3}, \mathrm{Ce}_{2} \mathrm{Co}_{7}\right.$, and $\left.\mathrm{Ce}_{5} \mathrm{Co}_{19}\right)$ coexist stably up to high temperatures, violating the empirical thermodynamic rule ${ }^{[16]}$ stating that two compounds with close chemistry should not both be stable over a wide temperature range. This implies that it is likely some compound phases reported in the Ce-Co system may be metastable or only stable for temperature ranges. Recall that the present FP calculations suggest that only $\mathrm{Ce}_{2} \mathrm{Co}_{7}$ is stable at low temperatures. Considering all the uncertainties in the Ce-Co system, the first treatment in Reference 43 was taken without alteration, because the Al-rich corner is the focus of this report. Clearly, further careful experiments are needed to clarify all the confusion in the Ce-Co phase diagram.

The thermodynamics of the Al-Ce system was assessed previously by Cacciamani et al. ${ }^{[46]}$ and recently by Gao et al. ${ }^{[17,25]}$ Because Gao et al. ${ }^{[17]}$ confirmed the $\mathrm{Al}_{4}$ Ce.tI10 as stable, opposing the previously claimed $\beta \mathrm{Al}_{11} \mathrm{Ce}_{3}$.tI10, ${ }^{[15,16]}$ and Gao et al. ${ }^{[17]}$ also confirmed a new phase $\mathrm{AlCe}_{2} . \mathrm{OP} 12$ stable at high temperature, the thermodynamic description of Reference 17 for the Al-Ce system was accepted for the Al-Ce-Co system. The $\mathrm{Al}_{2} \mathrm{Ce} . \mathrm{cF} 24$ was treated as a stoichiometric compound. ${ }^{[17]}$ The descriptions for the hypothetical $\mathrm{C} 15$ end members and antilattice are provided in Reference 25 .

The Al-Ce-Co ternary phase diagram assessed in Reference 20 is mainly based on the work by Zarechnyul et al. ${ }^{[21]}$ in 1980 , who constructed the partial $600^{\circ} \mathrm{C}$ isotherm in the range of 0 to 33.3 at. pct Ce. The ternary stoichiometric compounds assessed in Reference 20 include $\mathrm{Al}_{8} \mathrm{CeCo}_{2} . \mathrm{OP} 44,{ }^{[21]} \mathrm{Al}_{4}$ CeCo.oP12, ${ }^{[21]} \mathrm{Al}_{2} \mathrm{Ce}_{2}$ $\mathrm{Co}_{15} . \mathrm{hR} 19,{ }^{[4]} \mathrm{Al}_{4} \mathrm{Ce}_{3} \mathrm{Co}_{3} . \mathrm{OP}^{[48]}$ (the atomic position was not reported in Reference 48), AlCeCo.hP12, ${ }^{[49]}$ and AlCeCo.mC12. ${ }^{[50]}$ In addition, Zarechnyul et al. ${ }^{[21]}$ found three binary compounds that show ternary solubility between $\mathrm{Al}$ and $\mathrm{Co}$ atoms at $600{ }^{\circ} \mathrm{C}$. Specifically, Co solubility in $\mathrm{Al}_{2}$ Ce.cF24 is $\sim 10$ at. pet $\mathrm{Co}, \mathrm{Al}$ solubility in $\mathrm{CeCO}_{2} . \mathrm{cF} 24$ is $\sim 10$ at. pet $\mathrm{Al}$, and $\mathrm{Al}$ solubility in $\mathrm{CeCo}_{5} \cdot \mathrm{hP} 6$ is $\sim 20$ at. pet $\mathrm{Al}$.

\section{MODELING RESULTS AND DISCUSSION}

The Thermo-Calc package ${ }^{[51]}$ is used to optimize the ternary system using the PARROT module. The opti- mization is based on the experimental data from this study, such as DTA measurements, phase relationships, phase compositions, and phase crystal structures. It is usually difficult to obtain the liquidus temperatures accurately, and, furthermore, rare earth elements are susceptible to oxidation. Thus, the liquidus data are assigned with lower weight during optimization. In contrast, the invariant reaction temperatures are seen to be reproducible and thus more reliable, and they are set with higher weight during the global optimization. The thermodynamic parameters obtained in this study are listed in Table III. Figure 7 shows the calculated partial isopleths (vertical sections) through the $\mathrm{Al}-\mathrm{Co}-\mathrm{Ce}$ phase diagram at fixed $\mathrm{Ce}$ contents of 4 and 10 at. pct. Isopleths at fixed Co contents of 5 and 10 at. pct are shown in Figure 8. These figures illustrate how alloy compositions and temperature affect the equilibrium phase diagrams and demonstrate that the phase transformations during equilibrium solidification for compositions within the GFR are complicated. Figures 7 and 8 also show that the agreement is excellent between calculated phase transition temperatures and experimental DTA data. For other compositions whose DTA measurements were performed in this study, good agreement is also obtained.

Note that current thermodynamic descriptions predict that a reaction of $\beta \mathrm{Al}_{3} \mathrm{Ce}+\tau_{2} \leftrightarrow \mathrm{M}_{2} \mathrm{Ce}+\tau_{1}$ (Table IV) occurs at $\sim 1090{ }^{\circ} \mathrm{C}$, and consequently the composition triangle relationship among $\tau_{1}, \tau_{2}, \beta \mathrm{Al}_{3} \mathrm{Ce}$, and $\mathrm{M}_{2} \mathrm{Ce}$ changes when the temperature is raised from $1000{ }^{\circ} \mathrm{C}$ to $1100{ }^{\circ} \mathrm{C}$. This is not common because there is no additional solid phase formation, and no liquid is yet formed at these temperatures for both composition triangles. Surprisingly, the predicted invariant temperature for the reaction of $\beta \mathrm{Al}_{3} \mathrm{Ce}+\tau_{2} \leftrightarrow \mathrm{M}_{2} \mathrm{Ce}+\tau_{1}$ agrees extremely well with the DTA thermal events at $\sim 1089{ }^{\circ} \mathrm{C}$ recorded for alloys $\mathrm{Al}_{70} \mathrm{Ce}_{25} \mathrm{Co}_{5}$ and $\mathrm{Al}_{70} \mathrm{Ce}_{20}$ $\mathrm{Co}_{10}$ during heating segment (the DTA plots in Figure 5 and the thermal events marked in Figure 8).

A calculated liquidus surface projection with liquidus isocontours is presented in Figure 9. The solid lines refer to the univariant equilibria between the liquid and two solid phases, and three lines intersect at an invariant reaction point where four phases coexist at equilibrium.

Table III. Thermodynamic Parameters Obtained in the Present Study

\begin{tabular}{|c|c|}
\hline Phase & Parameter ( $\mathrm{J} / \mathrm{mol}$ of Atoms) \\
\hline \multirow[t]{3}{*}{ Liquid } & ${ }^{0} L_{\mathrm{Al}, \mathrm{Ce}, \mathrm{Co}}^{\mathrm{liq}}=+74,439-3.053 T$ \\
\hline & ${ }^{1} L_{\mathrm{Al}, \mathrm{Ce}, \mathrm{Co}}^{\mathrm{liq}}=-90,050+1.943 T$ \\
\hline & ${ }^{2} L_{\mathrm{Al}, \mathrm{Ce}, \mathrm{Co}}^{\mathrm{liq}}=+84,638+6.757 T$ \\
\hline \multirow[t]{3}{*}{$(\mathrm{Al}, \mathrm{Co})_{2} \mathrm{Ce}$} & ${ }^{0} L_{\mathrm{Al}, \mathrm{Co}: \mathrm{Ce}}^{(\mathrm{Al}, \mathrm{Co})_{2} \mathrm{Ce}}=-26423+5.257 T$ \\
\hline & ${ }^{1} L_{\mathrm{Al}, \mathrm{Co}: \mathrm{Ce}}^{(\mathrm{Al}, \mathrm{Co})_{2} \mathrm{Ce}}=+500$ \\
\hline & ${ }^{2} L_{\mathrm{Al}, \mathrm{Co}: \mathrm{Ce}}^{(\mathrm{Al}, \mathrm{Co})_{2} \mathrm{Ce}}=+5.0 T$ \\
\hline $\mathrm{Al}_{8} \mathrm{CeCo}_{2}\left(\tau_{1}\right)$ & $G_{\mathrm{Al}: \mathrm{Ce}: \mathrm{Co}}^{\tau_{1}}=811^{\circ} G_{\mathrm{Al}}^{\mathrm{fcc}}+111^{\circ} G_{\mathrm{Ce}}^{\mathrm{hcp}}+211^{\circ} G_{\mathrm{Co}}^{\mathrm{fcc}}-52,223+13.744 T$ \\
\hline $\mathrm{Al}_{4} \mathrm{CeCo}\left(\tau_{2}\right)$ & $G_{\mathrm{Al}: \mathrm{Ce}: \mathrm{Co}}^{\tau_{2}}=46^{\circ} G_{\mathrm{Al}}^{\mathrm{fcc}}+16^{\circ} G_{\mathrm{Ce}}^{\mathrm{hcp}}+16^{\circ} G_{\mathrm{Co}}^{\mathrm{fcc}}-54,802+12.705 T$ \\
\hline $\mathrm{AlCeCo}\left(\tau_{3}\right)$ & $G_{\mathrm{Al}: \mathrm{Ce}: \mathrm{Co}}^{\tau_{3}}=13^{\circ} G_{\mathrm{Al}}^{\mathrm{fcc}}+13^{\circ} G_{\mathrm{Ce}}^{\mathrm{hcp}}+13^{\circ} G_{\mathrm{Co}}^{\mathrm{fcc}}-54,296+8.146 T$ \\
\hline
\end{tabular}




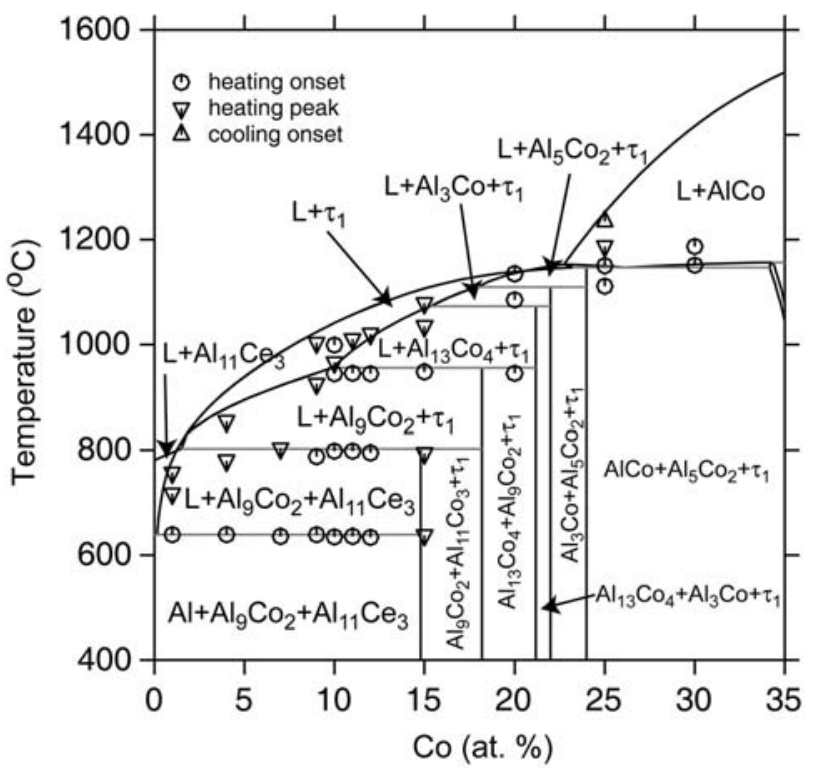

(a)

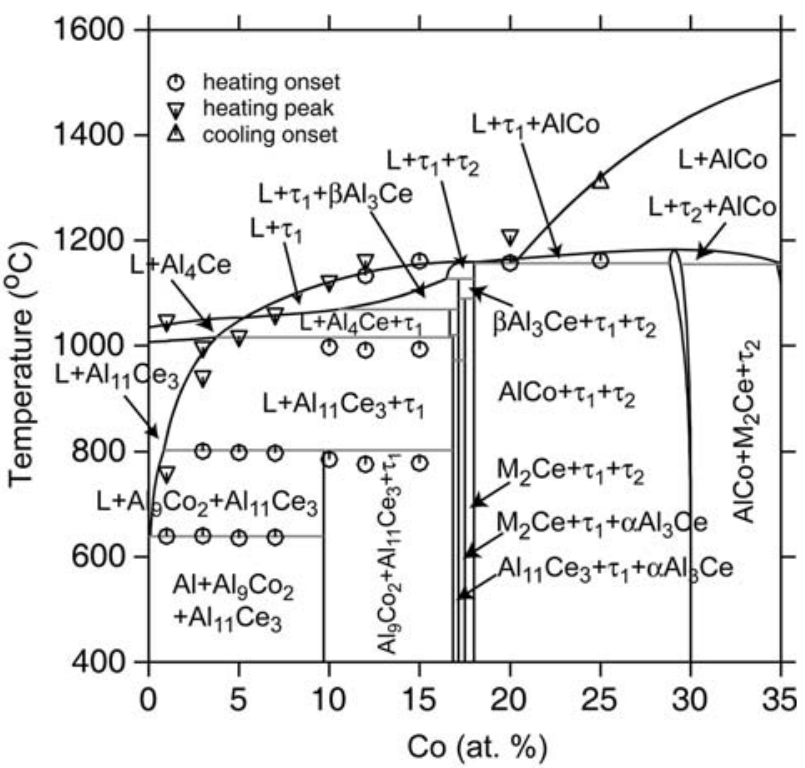

(b)

Fig. 7 - Calculated isopleth plot of (a) Al-4Ce-Co and (b) Al-10Ce-Co from the thermodynamic descriptions obtained in the present work.

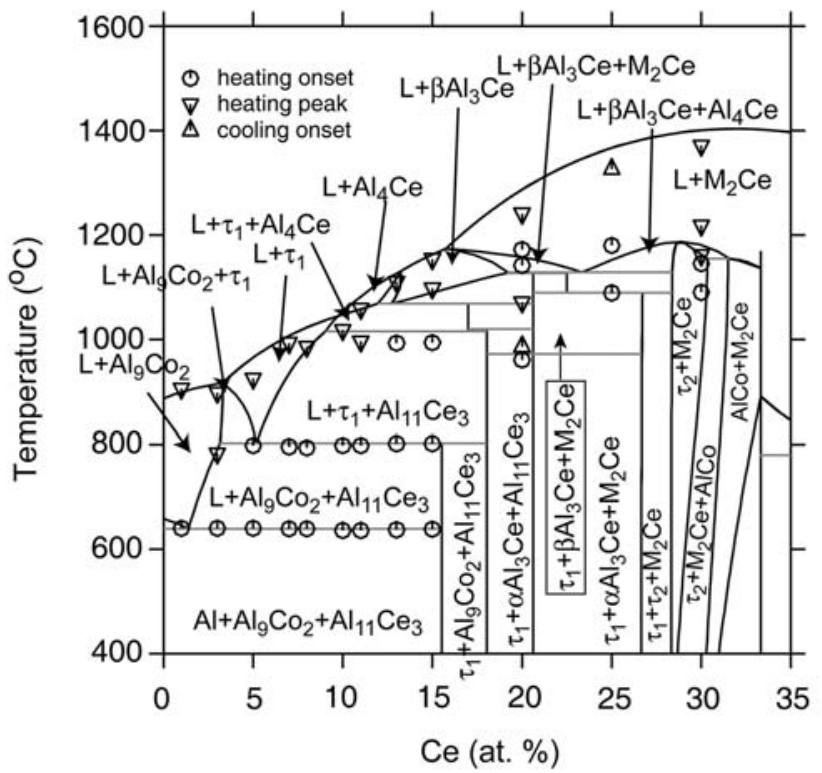

(a)

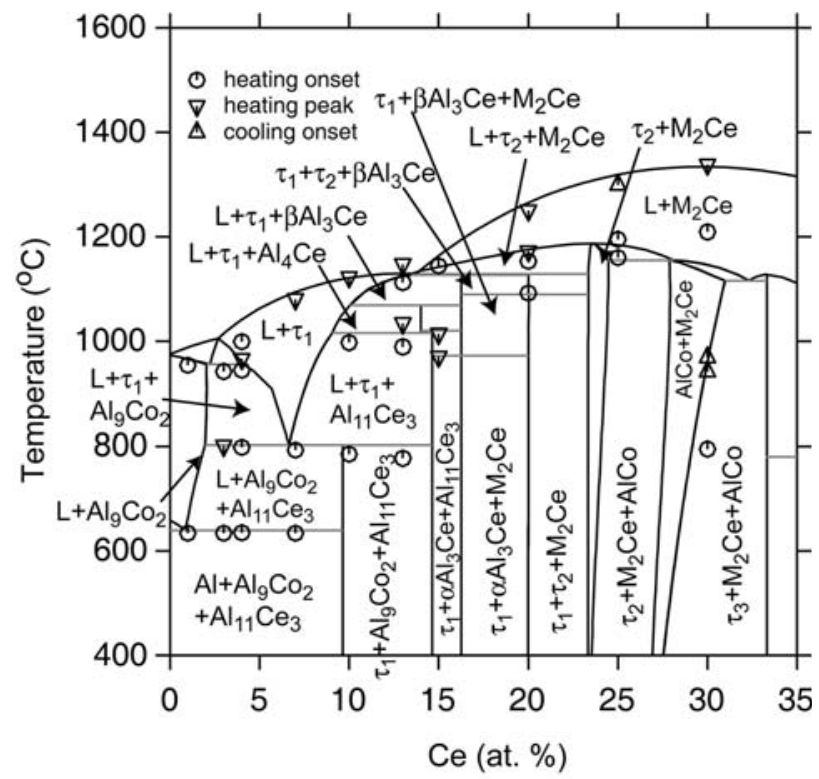

(b)

Fig. 8 - Calculated isopleth plots of (a) Al-Ce-5Co and (b) Al-Ce-10Co from the thermodynamic descriptions obtained in the present work.

All the invariant reactions involving the liquid (Figure 9) are listed in Table IV. The majority of the predicted invariant reaction temperatures agree exceptionally well with DTA measurements except for a few reactions including $\mathrm{U}_{3}, \mathrm{U}_{8}$, and $\mathrm{U}_{7}$ whose agreement is imperfect. For reaction $\mathrm{U}_{3} \quad\left(\mathrm{Al}_{4} \mathrm{Ce}+\tau_{1} \leftrightarrow L+\right.$ $\mathrm{Al}_{11} \mathrm{Ce}_{3}$ ), the current model slightly overestimated the reaction temperature but is still acceptable. This is thought to be due to possible stabilization of the $\mathrm{Al}_{4}$ Ce.tI10 by impurity or minor solute effects. In order to greatly improve agreement with the measured DTA data, the current authors then take a sublattice model of $(\mathrm{Al}, \mathrm{Co})_{4}(\mathrm{Ce})_{1}$ to model the $\mathrm{Al}_{4} \mathrm{Ce}$ phase, i.e., to allow $\mathrm{Co}$ atoms to mix with $\mathrm{Al}$ atoms. The resulting optimization finds that the agreement of $\mathrm{U}_{3}$ with experiments cannot be improved substantially unless a significant $\mathrm{Co}$ solubility ( $\geq 10$ at. pct) in $\mathrm{Al}_{4} \mathrm{Ce}$ is used, which, however, contradicts the present FP prediction that shows that $\mathrm{Al} / \mathrm{Co}$ substation in the ternary is very limited. Therefore, this treatment is not progressed further and is not 
Table IV. Invariant Reactions Obtained in the Present Study

\begin{tabular}{|c|c|c|c|c|c|}
\hline \multirow[b]{2}{*}{ Sym. } & \multirow{2}{*}{$\begin{array}{c}T\left({ }^{\circ} \mathrm{C}\right) \\
\text { Cal. }\end{array}$} & \multirow{2}{*}{$\begin{array}{c}T\left({ }^{\circ} \mathrm{C}\right) \\
\text { Exp. }\end{array}$} & \multicolumn{2}{|c|}{$X(L$, At. Pct $)$} & \multirow[b]{2}{*}{ Reaction $^{*}$} \\
\hline & & & $\mathrm{Co}$ & $\mathrm{Ce}$ & \\
\hline $\mathrm{E}_{1}$ & 639 & 640 & 0.2 & 1.9 & $L \leftrightarrow \mathrm{Al}_{11} \mathrm{Ce}_{3}+\mathrm{Al}_{9} \mathrm{Co}_{2}+\mathrm{Al}$ \\
\hline $\mathrm{U}_{1}$ & 803 & 798 & 1.3 & 4.1 & $L+\tau_{1} \leftrightarrow \mathrm{Al}_{11} \mathrm{Ce}_{3}+\mathrm{Al}_{9} \mathrm{Co}_{2}$ \\
\hline $\mathrm{U}_{2}$ & 955 & 945 & 7.6 & 2.6 & $L+\mathrm{Al}_{13} \mathrm{Co}_{4} \leftrightarrow \tau_{1}+\mathrm{Al}_{9} \mathrm{Co}_{2}$ \\
\hline $\mathrm{U}_{3}$ & 1015 & 996 & 4.1 & 9.0 & $\mathrm{Al}_{4} \mathrm{Ce}+\tau_{1} \leftrightarrow L+\mathrm{Al}_{11} \mathrm{Ce}_{3}$ \\
\hline $\mathrm{U}_{4}$ & 1068 & 1073 & 5.9 & 10.5 & $L+\beta \mathrm{Al}_{3} \mathrm{Ce} \leftrightarrow \mathrm{Al}_{4} \mathrm{Ce}+\tau_{1}$ \\
\hline $\mathrm{U}_{5}$ & 1073 & 1085 & 14.6 & 2.6 & $L+\mathrm{Al}_{3} \mathrm{Co} \leftrightarrow \mathrm{Al}_{13} \mathrm{Co}_{4}+\tau_{1}$ \\
\hline $\mathrm{U}_{6}$ & 1090 & 1089 & - & - & $\beta \mathrm{Al}_{3} \mathrm{Ce}+\tau_{2} \leftrightarrow \mathrm{M}_{2} \mathrm{Ce}+\tau_{1}$ \\
\hline $\mathrm{U}_{7}$ & 1110 & 1135 & 17.9 & 2.8 & $L+\mathrm{Al}_{5} \mathrm{Co}_{2} \leftrightarrow \mathrm{Al}_{3} \mathrm{Co}+\tau_{1}$ \\
\hline $\mathrm{E}_{2}$ & 1116 & - & 21.1 & 28.6 & $L \leftrightarrow \mathrm{AlCo}+\mathrm{M}_{2} \mathrm{Ce}+\tau_{3}$ \\
\hline $\mathrm{U}_{8}$ & 1127 & 1143 & 9.7 & 13.6 & $L+\tau_{2} \leftrightarrow \beta \mathrm{Al}_{3} \mathrm{Ce}+\tau_{1}$ \\
\hline $\mathrm{U}_{9}$ & 1128 & - & 9.7 & 13.7 & $L+\mathrm{M}_{2} \mathrm{Ce} \leftrightarrow \tau_{2}+\beta \mathrm{Al}_{3} \mathrm{Ce}$ \\
\hline $\mathrm{U}_{10}$ & 1147 & 1151 & 22.2 & 4.8 & $L+\mathrm{AlCo} \leftrightarrow \mathrm{Al}_{5} \mathrm{Co}_{2}+\tau_{1}$ \\
\hline $\mathrm{U}_{11}$ & 1155 & 1162 & 19.6 & 21.5 & $L+\tau_{2} \leftrightarrow \mathrm{AlCo}+\mathrm{M}_{2} \mathrm{Ce}$ \\
\hline $\mathrm{E}_{3}$ & 1156 & 1159 & 20.6 & 9.0 & $L \leftrightarrow \mathrm{AlCo}+\tau_{1}+\tau_{2}$ \\
\hline $\mathrm{U}_{12}$ & 1192 & - & 2.8 & 16.6 & $L+\mathrm{M}_{2} \mathrm{Ce} \leftrightarrow \mathrm{Al}_{4} \mathrm{Ce}+\beta \mathrm{Al}_{3} \mathrm{Ce}$ \\
\hline
\end{tabular}

${ }^{*}$ The phases on the left-hand side are higher-temperature phases, and those on the right-hand side are lower-temperature phases.

presented here. For reactions $\mathrm{U}_{8} \quad\left(L+\tau_{2} \leftrightarrow\right.$ $\left.\beta \mathrm{Al}_{3} \mathrm{Ce}+\tau_{1}\right)$ and $\mathrm{U}_{9}\left(L+\mathrm{M}_{2} \mathrm{Ce} \leftrightarrow \tau_{2}+\beta \mathrm{Al}_{3} \mathrm{Ce}\right)$, their reaction temperature and liquid composition are so close to each other that their thermal events overlap during DTA measurements. This makes precise determination of the onset temperature for each reaction difficult. For reaction $\mathrm{U}_{7}\left(L+\mathrm{Al}_{5} \mathrm{Co}_{2} \leftrightarrow \mathrm{Al}_{3} \mathrm{Co}+\tau_{1}\right)$, the uncertainty in reaching equilibrium state for $\mathrm{Al}_{3} \mathrm{Co}$ and $\mathrm{Al}_{5} \mathrm{Co}_{2}{ }^{[30-34]}$ may be responsible for the imperfect agreement on the reaction temperature with DTA measurement.

The liquidus surface projection and isocontours (Figure 9) show that increasing $\mathrm{Ce}$ or Co contents in the alloy monotonically raises the liquidus temperature (beyond the ternary eutectic point $E_{1}$ ), and the compositions within the GFR have liquidus temperatures that lie between $\sim 900{ }^{\circ} \mathrm{C}$ and $\sim 1125^{\circ} \mathrm{C}$. The ternary $\tau_{1}$ compound has the broadest primary compositional field in the Al-rich corner, so it is mainly responsible for the liquidus temperature of alloys within the GFR, and thus impacts the glass formation the most. On the other hand, the ternary $\tau_{2}$ compound has less impact on the glass formation, and the primary $\tau_{2}$ phase field has a nearly plateau liquidus temperature of $1175^{\circ} \mathrm{C}$. Further, the observed GFR is very narrow and is mainly limited by the wide phase fields of the primary $\mathrm{M}_{2} \mathrm{Ce}$ and $\mathrm{AlCo}$, which both are very stable in the edge binaries and the ternary and impact the ternary phase equilibria substantially. In order to improve the GFA and broaden the GFR in the AlCe-Co system, an alloying strategy could be sought to lower the melting point of the ternary $\tau_{1}$ compound and destabilize $\mathrm{M}_{2} \mathrm{Ce}$ and AlCo solution compounds as one effective measure.

Previous work by Gao et al. ${ }^{[17]}$ showed that (1) a polymorphous transition of $\beta \mathrm{Al}_{3} \mathrm{Ce} \leftrightarrow \alpha \mathrm{Al}_{3} \mathrm{Ce}$ occurs at $\sim 973{ }^{\circ} \mathrm{C}$ and (2) a catetectic $\mathrm{Al}_{4} \mathrm{Ce} \leftrightarrow L+\mathrm{Al}_{11} \mathrm{Ce}_{3}$ occurs at $1006{ }^{\circ} \mathrm{C}$ in the Al-Ce binary. For the Al-CeCo ternary, the $\alpha / \beta \mathrm{Al}_{3} \mathrm{Ce}$ transition temperature measured in this study is found to fluctuate slightly, i.e.,
$961{ }^{\circ} \mathrm{C}$ to $970{ }^{\circ} \mathrm{C}$, but fairly close to that in the binary, i.e., $\sim 973{ }^{\circ} \mathrm{C}$ (Figure 7 and the first thermal event marked for alloys $\mathrm{Al}_{75} \mathrm{Ce}_{20} \mathrm{Co}_{5}$ and $\mathrm{Al}_{75} \mathrm{Ce}_{15} \mathrm{Co}_{10}$ in Figure 8). Therefore, it is further confirmed that the polymorphism of $\alpha / \beta \mathrm{Al}_{3} \mathrm{Ce}$ exists in the $\mathrm{Al}-\mathrm{Ce}$ system. ${ }^{[17]}$ The slight decrease in the $\alpha / \beta \mathrm{Al}_{3} \mathrm{Ce}$ transition temperature in the Al-Ce-Co ternary may be due to the possibility of small Co solid solution in $\beta \mathrm{Al}_{3} \mathrm{Ce}$ or other unidentified reasons. Due to lack of direct measurement of relevant Co solubility data, this possibility is not considered in the current thermodynamics modeling. On the other hand, the binary catetectic reaction of $\mathrm{Al}_{4} \mathrm{Ce} \leftrightarrow L+\mathrm{Al}_{11} \mathrm{Ce}_{3}$ becomes the reaction of $\mathrm{Al}_{4} \mathrm{Ce}+\tau_{1} \leftrightarrow L+\mathrm{Al}_{11} \mathrm{Ce}_{3}$ in the Al-Ce-Co ternary that occurs at $996{ }^{\circ} \mathrm{C} \pm 6{ }^{\circ} \mathrm{C}$. Such a change in the reaction temperature provides further experimental support that the phase transition between $\mathrm{Al}_{4} \mathrm{Ce}$ and $\mathrm{Al}_{11} \mathrm{Ce}_{3}$ cannot be polymorphous. ${ }^{[17]}$

The present study indicates that reliable CALPHAD modeling can be used to interpret DTA measurements with high confidence. This is useful because there are often several thermal events for each alloy (Figures 5, 7, and 8 ), and it is not possible to immediately determine the reaction type (i.e., eutectic, eutectoid, etc.) and exact phases involved in each thermal event for each alloy if only the DTA plot is available. The thermodynamics of $\mathrm{Al}-\mathrm{Ce}-\mathrm{Co}$ in the present work are determined through the classical CALPHAD approach, and the values of the formation enthalpies of the ternary compounds (Table III) through the CALPHAD optimization scheme are found to be comparable with those from FP calculations (Table I). In fact, employment of FP calculations into phase diagram studies and further integration of FP calculations into CALPHAD modeling have become very active and important in the community of phase diagram research. Clearly, integrating FP calculations into phase diagram research will play an indispensable role especially for the multicomponent system, in addition to critical experiments and CALPHAD modeling. ${ }^{[13,29,52-61]}$ 


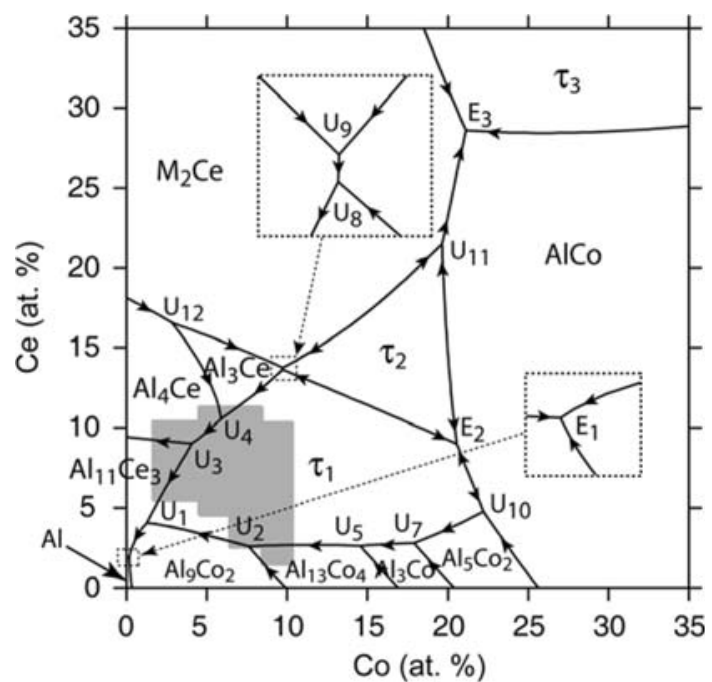

(a)

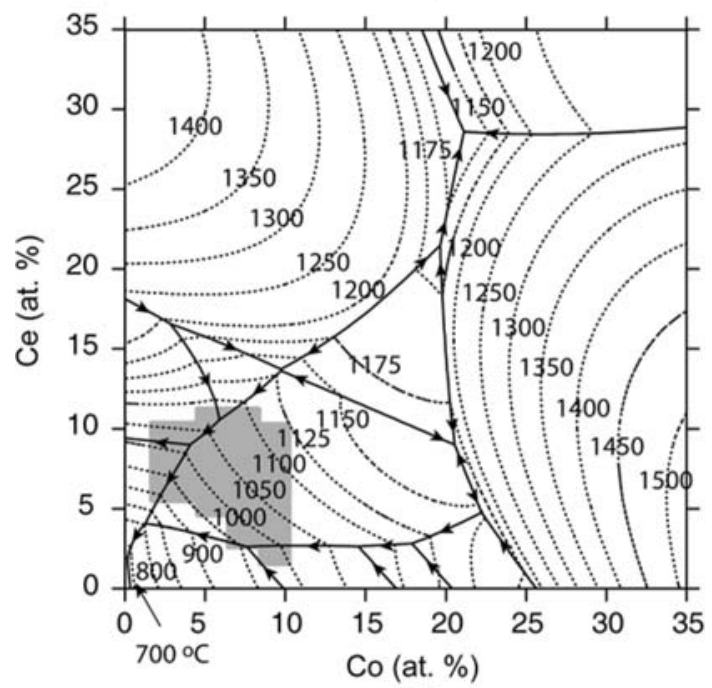

(b) ture is likely to be isostructural with $\mathrm{Al}_{5} \mathrm{CeNi}_{2}$.oI16, as suggested by FP calculations.

4. This investigation further confirmed the earlier statements by Gao et al. ${ }^{[1]}$ that (a) a polymorphous transformation of $\alpha / \beta \mathrm{Al}_{3} \mathrm{Ce}$ exists in the Al-Ce binary system; and (b) the transformation between $\mathrm{Al}_{11} \mathrm{Ce}_{3} . \mathrm{OI} 28$ and $\mathrm{Al}_{4} \mathrm{Ce} . \mathrm{tI} 10$ cannot be polymorphous, disagreeing with the assessed phase diagram handbooks. ${ }^{[15,16]}$

5. The Co solubility in the $\mathrm{Al}_{2}$ Ce.cF24 was found to be $\sim 2.5$ at. pet at $500{ }^{\circ} \mathrm{C}$, which is significantly smaller than reported by Zarechnyul et al. ${ }^{[21]}$ The phase relation in its vicinity was revised accordingly.

6. The FP calculations show that none of the Al-Ce binary compounds has extended Co solubility into the ternary at high temperatures. The enthalpy penalty for $\mathrm{Al} / \mathrm{Co}$ mixing is too high to be compensated by the entropy gain.

7. The Al-rich Al-Ce-Co system was thermodynamically optimized for the first time. Agreement between the calculated phase boundary and DTA data is obtained. The enthalpies of formation for the ternary compounds obtained from CALPHAD modeling are comparable to those from FP calculations.

\section{ACKNOWLEDGMENTS}

The authors acknowledge the financial support from a Multi-University Research Initiative (Grant No. F49602-01-1-0352). Partial financial support is also acknowledged from the Computational Materials Science Network, a program of the Office of Science, United States Department of Energy (Grant Nos. NSF/ DMR-0520425 and NSF/DMR-0111198).

\section{REFERENCES}

Fig. 9-(a) liquidus surface projection and (b) liquidus isocontours calculated from the thermodynamic descriptions obtained in the present work. The solid lines are univariant equilibria and the primary crystallization phase field is labeled. The dotted lines are the liquidus isotherms, and the arrows indicate the downward temperature gradient. The shaded area represents the GFR identified in the present work.

\section{CONCLUSIONS}

The Al-rich Al-Ce-Co system was investigated using a range of experimental techniques and FP energy calculation, reaching the following new conclusions.

1. The GFR was determined using a constant circumferential speed of $48 \mathrm{~ms}^{-1}$. It is slightly narrower than reported by Inoue et al., ${ }^{[2]}$ and the slight disagreement is probably a result of the different quenching rate or quenching environment used.

2. There are three stoichiometric compounds confirmed, namely, $\mathrm{Al}_{8} \mathrm{CeCo}_{2} . \mathrm{oP} 44\left(\tau_{1}\right), \mathrm{Al}_{4} \mathrm{CeCo.oP} 12$ $\left(\tau_{2}\right)$, and AlCeCo.mC12 $\left(\tau_{3}\right)$.

3. A metastable stoichiometric compound with a composition of $\mathrm{Al}_{5} \mathrm{CeCo}_{2}$ was discovered, and its struc-
1. Y. He, S.J. Poon, and G.J. Shiflet: Science, 1988, vol. 241, pp. $1640-42$

2. A. Inoue, K. Ohtera, A.P. Tsai, and T. Masumoto: Jpn. J. Appl. Phys. Lett., 1988, vol. 27, pp. L280-L282.

3. W.L. Johnson, A. Inoue, and C.T. Liu: Bulk Metallic Glasses, Materials Research Society Symposia Proceedings, MRS, Warrendale, PA, 1999, vol. 554.

4. D.B. Miracle, W.S. Sanders, and O.N. Senkov: Phil. Mag., 2003, vol. 83, pp. 2409-28.

5. F.Q. Guo, S.J. Poon, and G.J. Shiflet: Appl. Phys. Lett., 2004, vol. 84 , pp. $37-39$.

6. N. Saunders and A.P. Miodownik: Mater. Sci. Technol., 1988, vol. 4, pp. 768-77.

7. X.H. Lin and W.L. Johnson: J. Appl. Phys., 1995, vol. 78, pp. 6514-9.

8. X.P. Tang, U. Geyer, R. Busch, W.L. Johnson, and Y. Wu: Nature, 1999, vol. 402, pp. 160-2.

9. F. Faupel, W. Frank, M.P. Macht, H. Mehrer, V. Naundorf, K. Ratzke, H.R. Schober, S.K. Sharma, and H. Teichler: Rev. Mod. Phys., 2003, vol. 75, pp. 237-80.

10. R. Busch, Y.J. Kim, and W.L. Johnson: J. Appl. Phys., 1995, vol. 77, pp. 4039-43.

11. H. Chen, Y. He, G.J. Shiflet, and S.J. Poon: Scripta Metall., 1991, vol. 25 , pp. 1421-24.

12. F. Szuecs, C.P. Kim, and W.L. Johnson: Acta Mater., 2001, vol. 49 , pp. $1507-13$. 
13. M.C. Gao and G.J. Shiflet: Scripta Mater., 2005, vol. 53, pp. 1129 34.

14. R.E. Hackenberg, M.C. Gao, L. Kaufman, and G.J. Shiflet: Acta Mater., 2002, vol. 50, pp. 2245-58.

15. T.B. Massalski, H. Okamoto, P.R. Subramanian, and L. Kacprzak: Binary Alloy Phase Diagrams, ASM INTERNATIONAL, Materials Park, OH, 1990.

16. H. Okamoto: Desk Handbook Phase Diagrams for Binary Alloys, ASM INTERNATIONAL, Materials Park, OH, 2000.

17. M.C. Gao, N. Unlu, G.J. Shiflet, M. Mihalkovic, and M. Widom: Metall. Mater. Trans. A, 2005, vol. 36A, pp. 3269-79.

18. R.O. Jones and O. Gunnarsson: Rev. Mod. Phys., 1989, vol. 61, pp. 689-746.

19. A.N. Mansour, C.P. Wong, and R.A. Brizzolara: Phys. Rev. B, 1994, vol. 50, pp. 12401-12.

20. P. Villars, A. Prince, and H. Okamoto: Handbook of Ternary Alloy Phase Diagrams, ASM INTERNATIONAL, Materials Park, OH, 1995.

21. O.S. Zarechnyuk, Z.M. Rykhal, and V.V. Korin: Dopo. Akad. Nauk Ukr. A Fiziko.-Mater. Tekh Nauki, 1980, vol. 42, pp. 84-85.

22. G. Kresse and J. Hafner: Phys. Rev. B, 1993, vol. 47, pp. 558-61.

23. G. Kresse and J. Furthmueller: Phys. Rev. B, 1996, vol. 54, pp. 11169-86.

24. G. Kresse and D. Joubert: Phys. Rev. B, 1999, vol. 59, pp. 1758 75.

25. M.C. Gao, A.D. Rollett, and M. Widom: CALPHAD, 2006, vol. 30 , pp. $341-48$.

26. J.P. Perdew, K. Burke, and M. Ernzerhof: Phys. Rev. Lett., 1996, vol. 77 , pp. $3865-8$.

27. http://alloy.phys.cmu.edu (special "published" entries).

28. M. Mihalkovič and M. Widom: Phys. Rev. B, 2007, vol. 75, p. 014207.

29. M. Mihalkovic and M. Widom: Phys. Rev. B, 2004, vol. 70, p. 144107.

30. X.L. Ma and K.H. Kuo: Metall. Mater. Trans. A, 1994, vol. 25A, pp. $47-56$.

31. T. Godecke and M. Ellner: Z. Metallkd., 1996, vol. 87, pp. 854-64.

32. B. Grushko, R. Wittenberg, K. Bickman, and C. Freiburg: J. Alloys Compd., 1996, vol. 233, pp. 279-87.

33. T. Godecke: Z. Metallkd., 1997, vol. 88, pp. 904-10.

34. B. Grushko, C. Freiburg, K. Bickmann, and R. Wittenberg: $Z$. Metallkd., 1997, vol. 88, pp. 379-81.

35. M. Mihalkovič and M. Widom: MRS Symp. Proc., 2004, vol. 805, p. LL2.3.

36. M.C. Gao, G.J. Shiflet, M. Mihalkovic, and M. Widom: University of Virginia, unpublished research, 2002-2004.

37. E. Cockayne and M. Widom: Phys. Rev. Lett., 1998, vol. 81, pp. 598-601.
38. M. Hillert and L.I. Staffanson: Acta Chem. Scand., 1970, vol. 24, pp. 3618-26.

39. A.T. Dinsdale: CALPHAD, 1991, vol. 15, pp. 317-425.

40. O. Redlich and A.T. Kister: Ind. Eng. Chem., 1948, vol. 40, pp. 345-8.

41. Y.M. Muggianu, M. Gambino, and J.P. Bros: J. Chim. Phys., 1975, vol. 22, pp. 83-88.

42. N. Dupin and I. Ansara: Rev. Metall.-Cahiers D Info. Technol., 1998, vol. 95, pp. 1121-9.

43. X.P. Su, W.J. Zhang, and Z.M. Du: J. Alloys Compd., 1998, vol. 267 , pp. 121-7.

44. C.H. Wu, Y.C. Chuang, and X.M. Jin: J. Alloys Compd., 1992, vol. 179 , pp. $27-35$.

45. H.H. Stadelmaier, B. Reinsch, and G. Petzow: Z. Metallkd., 1998, vol. 89, pp. 114-8.

46. G. Cacciamani and R. Ferro: CALPHAD, 2001, vol. 25, pp. 58397.

47. O.S. Zarechnyuk and P.I. Kripyakevich: Sov. Phys.-Cryst., 1962, vol. 7 , p. 436.

48. G. Cordier, G. Dorsam, and R. Kniep: J. Magn. Magn. Mater., 1988, vol. 76, pp. 653-4.

49. R.C. Mansey, G.V. Raynor, and I.R. Harris: J. Less-Common Met., 1968, vol. 14, pp. 337-47.

50. N. Grin Yu, O.M. Sichevich, V.A. Bruskov, R.M. Rykhal, and P. Yarmolyuk Ya: Sov. Phys.-Cryst., 1983, vol. 28, p. 346.

51. B. Sundman, B. Jansson, and J.O. Andersson: CALPHAD, 1985 , vol. 9, pp. 153-90.

52. M. Asta, R. McCormack, and D. de Fontaine: Phys. Rev. B, 1993, vol. 48 , pp. $748-66$

53. V. Ozolins, C. Wolverton, and A. Zunger: Phys. Rev. B, 1998, vol. 57, pp. 6427-43.

54. M. Asta and V. Ozolins: Phys. Rev. B, 2001, vol. 64, p. 094104

55. C. Wolverton: Acta Mater., 2001, vol. 49, pp. 3129-42.

56. C. Wolverton, X.Y. Yan, R. Vijayaraghavan, and V. Ozolins: Acta Mater., 2002, vol. 50, pp. 2187-97.

57. Y. Wang, S. Curtarolo, C. Jiang, R. Arroyave, T. Wang, G. Ceder, L.Q. Chen, and Z.K. Liu: CALPHAD, 2004, vol. 28, pp. 79-90.

58. Y. Zhong, C. Wolverton, Y.A. Chang, and Z.K. Liu: Acta Mater., 2004, vol. 52, pp. 2739-54

59. G. Ghosh and M. Asta: Acta Mater., 2005, vol. 53, pp. 3225-52.

60. K. Ozturk, Y. Zhong, L.Q. Chen, C. Wolverton, J.O. Sofo, and Z.K. Liu: Metall. Mater. Trans. A, 2005, vol. 36A, pp. 5-13.

61. P.E.A. Turchi, V. Drchal, J. Kudrnovsky, C. Colinet, L. Kaufman, and Z.K. Liu: Phys. Rev. B, 2005, vol. 71, p. 094206.

62. P. Villars: Pearson's Handbook,Desk ed., ASM INTERNATIONAL, Metals Park, OH, 1995. 